\title{
Clary Sage Cultivation and Mycorrhizal Inoculation Influence the Rhizosphere Fungal Community of an Aged Trace-Element Polluted Soil
}

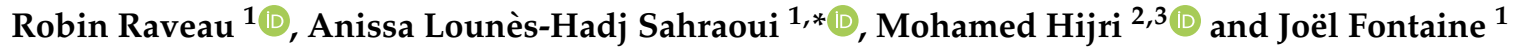 \\ 1 Unité de Chimie Environnementale et Interactions sur le Vivant (UCEIV), Université du Littoral Côte d'Opale, \\ UR 4492, SFR Condorcet FR CNRS 3417, 50 rue Ferdinand Buisson, CEDEX, 62228 Calais, France; \\ robin.raveau@univ-littoral.fr (R.R.); fontaine@univ-littoral.fr (J.F.) \\ 2 Institut de Recherche en Biologie Végétale (IRBV) de l'Université de Montréal, 4101 Rue Sherbrooke E, \\ Montréal, QC H1X2B2, Canada; mohamed.hijri@umontreal.ca \\ 3 African Genome Center, Mohammed VI Polytechnic University (UM6P), Lot 660, Hay Moulay Rachid, \\ Ben Guerir 43150, Morocco \\ * Correspondence: anissa.lounes@univ-littoral.fr
}

\section{check for} updates

Citation: Raveau, R.; Lounès-Hadj Sahraoui, A.; Hijri, M.; Fontaine, J. Clary Sage Cultivation and Mycorrhizal Inoculation Influence the Rhizosphere Fungal Community of an Aged Trace-Element Polluted Soil. Microorganisms 2021, 9, 1333. https:// doi.org/10.3390/

microorganisms 9061333

Academic Editors: Persiani Anna Maria and Solveig Tosi

Received: 25 May 2021

Accepted: 17 June 2021

Published: 19 June 2021

Publisher's Note: MDPI stays neutral with regard to jurisdictional claims in published maps and institutional affiliations.

Copyright: (c) 2021 by the authors. Licensee MDPI, Basel, Switzerland. This article is an open access article distributed under the terms and conditions of the Creative Commons Attribution (CC BY) license (https:/ / creativecommons.org/licenses/by/ $4.0 /)$.

\begin{abstract}
Soil fungal communities play a central role in natural systems and agroecosystems. As such, they have attracted significant research interest. However, the fungal microbiota of aromatic plants, such as clary sage (Salvia sclarea L.), remain unexplored. This is especially the case in trace element (TE)-polluted conditions and within the framework of phytomanagement approaches. The presence of high concentrations of TEs in soils can negatively affect not only microbial diversity and community composition but also plant establishment and growth. Hence, the objective of this study is to investigate the soil fungal and arbuscular mycorrhizal fungi (AMF) community composition and their changes over time in TE-polluted soils in the vicinity of a former lead smelter and under the cultivation of clary sage. We used Illumina MiSeq amplicon sequencing to evaluate the effects of in situ clary sage cultivation over two successive years, combined or not with exogenous AMF inoculation, on the rhizospheric soil and root fungal communities. We obtained 1239 and 569 fungal amplicon sequence variants (ASV), respectively, in the rhizospheric soil and roots of $S$. sclarea under TE-polluted conditions. Remarkably, 69 AMF species were detected at our experimental site, belonging to 12 AMF genera. Furthermore, the inoculation treatment significantly shaped the fungal communities in soil and increased the number of AMF ASVs in clary sage roots. In addition, clary sage cultivation over successive years could be one of the explanatory parameters for the inter-annual variation in both fungal and AMF communities in the soil and root biotopes. Our data provide new insights on fungal and AMF communities in the rhizospheric soil and roots of an aromatic plant, clary sage, grown in TE-polluted agricultural soil.
\end{abstract}

Keywords: trace element-polluted soils; mycobiota; Salvia sclarea; arbuscular mycorrhizal fungi

\section{Introduction}

Microbial communities play major roles in soil ecosystems and provide a wide range of services, notably being involved in nutrient biogeochemical cycles, carbon sequestration, and the provisioning of clean air and water [1-4]. Among soil microbial communities, fungi represent important biomass, providing the key function of organic matter decomposition leading to nutrient cycling and performing crucial roles in humification, mineralization, and soil aggregation processes $[5,6]$. Hence, fungi play a central role in the functioning and fertility of most natural and managed ecosystems [3,5-7]. Some fungi, such as arbuscular mycorrhizal fungi (AMF) belonging to the phylum Glomeromycota, are additionally able to form symbiotic associations with more than $80 \%$ of terrestrial plants [8]. Being ubiquitous microorganisms in the soil and obligate biotrophs, they contribute to plant health, growth, and productivity and, in that regard, are particularly valuable and well-characterized 
in agricultural soils $[3,9,10]$. AMF contribution to agroecosystem functioning has been particularly well-studied [3], as they provide many benefits to their host plant through improved water and mineral supply and can mitigate the adverse effects of biotic and abiotic stresses including soil pollutant damages [10-13].

Soil pollution by trace elements (TEs) is a worldwide concern due to the major threat they represent, not only to human health, but also to environmental health and ecosystem functioning, due to their non-biodegradability, bioaccumulation, and potent toxicity $[6,11]$. Notably, TEs can accumulate in cultivated plants, causing growth and productivity issues as well as possible contamination of the food chain, which may be responsible for various disorders and diseases in human beings [11,14-16]. It has previously been shown that revegetation of TE-polluted areas could help towards restoring the disturbed ecosystem's functioning, as well as providing aesthetic value and a reduction in wind and water erosion phenomena $[7,17,18]$. In that regard, among other potential remediation options, phytomanagement has attracted significant attention. It combines risk-mitigation methods with sustainable and profitable land-uses to reclaim TE-polluted sites. Based on phytotechnologies, it relies on the ability of plants and their associated microorganisms to naturally immobilize inorganic pollutants, such as TEs, in their rhizosphere [18-20]. In order for phytomanagement strategies to be an environmentally sustainable and economically viable process, plant biomass valorization is a major component. At present, research is primarily focused on energy crops, such as willow or miscanthus, intended for bioenergy production [21-23]. Nonetheless, the cultivation of aromatic plants destined for essential oil (EO) production could represent both an innovative and economically viable alternative for reclaiming TE-polluted areas. Essential oils, as high-added value products, may be valuable in various fields, such as perfumery and cosmetics, medicine, or food industries. As an example, clary sage (Salvia sclarea L.) is a xerophytic aromatic plant native to the Mediterranean area, which is able to grow relatively quickly and to develop a sustainable vegetative cover over two or three successive years, thanks to its short-lived perennial life cycle [24-27]. This Lamiaceae is also able to produce large amounts of biomass, especially in its second cultivation year, resulting in significant EO production, which is valuable to the food and cosmetics industries but is also well known for its antimicrobial and antiseptic properties [24,27-29].

The cautious selection of the plant species, based on its ability to grow in conditions that are toxic to most plants, is another key criterion towards successful phytomanagement $[18,21]$. Therefore, the use of exogenous amendments-either mineral, organic, or microbial-could support plant growth and health. Thus, microbial inoculants, such as AMF or ectomycorrhizal fungi, have previously been evaluated in field trials [30] and were found to improve plant growth, as well as contributing to TEs immobilization, through either precipitation or complexation phenomena occurring in the rhizosphere [11,18,31]. However, the impact of exogenous AMF amendments on the fungal and AMF community compositions, even though it has previously been investigated, remains unclear. Contrasting results have been published. Some reports indicate a clear shaping of the microbial communities in response to AMF inoculation [9,10,32-34]; however, some others have demonstrated no influence of inoculation on the native fungal or AMF communities in the rhizosphere $[35,36]$. For instance, it was described that inoculating with Glomus sp. changed the abundance of indigenous AMF and of other fungal members while consistently enriching several bacterial operational taxonomic units [32]. Similarly, inoculating with a Rhizophagus irregularis strain resulted in a suppression of the plant roots' colonization by native AMF taxa and decreased the diversity of the root-colonizing AMF community [9]. AMF affects the soil microorganisms in the rhizosphere of their host plant, leading to the formation of a specific area in the soil called the mycorrhizosphere, as they compete for nutrients and space and exchange complex chemicals to interact with each other [37,38]. In contrast, Ref. [35] demonstrated that inoculation with Rhizophagus irregularis DAOM-197198 did not influence either the AMF community diversity in roots or the indigenous AMF community composition. The authors suggest that the indigenous AMF community could 
be highly abundant and more adapted to both their host plant and the environmental conditions and hence more resilient to external factors such as exogenous inoculation [35].

From the same perspective, even though the short-term effects of TE pollution on microbial communities are well-known, usually leading to a decrease in both richness and abundance of fungal species $[13,14,16]$, the assessment of aged TE pollution in the long-term has been poorly investigated [17]. Furthermore, plant identity has also been demonstrated as a key factor in shaping the microbial communities and, as such, should be carefully evaluated $[17,38,39]$. In regards to the above, AMF inoculation and plant identity are likely to result in a shift of the fungal and AMF communities in the rhizosphere of the cultivated plant, as well as their respective structuring impact on the communities should be evaluated.

Hence, studying fungal community composition in such conditions could facilitate an understanding of the below-ground ecosystem's functioning, as well as to potentially identify unique and TE-well-adapted fungal species. From a wider perspective, the identification of fungal species capable of growing in TE-polluted conditions could provide a knowledge basis for the development of remediation methods. Thus, the present study aimed to: (I) Characterize the indigenous fungal and AMF community compositions in TE-aged polluted soil; (II) evaluate and monitor the potential structural changes induced in plant rhizosphere communities by the cultivation of $S$. sclarea over its whole life cycle; (III) assess the effects of the addition of a commercial mycorrhizal inoculum on the native fungal communities, including AMF, over the clary sage life cycle.

\section{Materials and Methods}

\subsection{Experimental Site}

This study was carried out on an aged TE-polluted site $\left(50^{\circ} 25^{\prime} 55.5^{\prime \prime} \mathrm{N}, 3^{\circ} 02^{\prime} 25.5^{\prime \prime} \mathrm{E}\right.$; altitude $23 \mathrm{~m}$ ) in the north of France. The area is characterized by a warm, temperate, and humid climate with cool summers. The climatic conditions are marked by average annual precipitation of $742.5 \mathrm{~mm}$ and a mean annual temperature of $12{ }^{\circ} \mathrm{C}$, ranging from $3.6^{\circ} \mathrm{C}$ in January to $20.3^{\circ} \mathrm{C}$ in July (Infoclimat, accessed on 3 March 2020).

The site is a former agricultural field with a size of $1.3 \mathrm{ha}$. It is located $600 \mathrm{~m}$ away from a former $\mathrm{Pb}$ and $\mathrm{Zn}$ smelter, Metaleurop Nord, whose activities over more than a century generated significant amounts of TE-containing dust, which led to topsoil $(0-30 \mathrm{~cm}) \mathrm{TE}$ pollution [40,41]. The topsoil is characterized by high amounts of $\mathrm{Cd}, \mathrm{Pb}$, and $\mathrm{Zn}$, which correspond to concentrations approximately 17-, 11-, and 6-fold higher, respectively, than those reported in regional background levels for agricultural soils [42,43]. The soil texture consists of silt loam with a slightly alkaline water $\mathrm{pH}$ (7.9). The soil physicochemical properties were homogenous across the experimental plot. Full descriptions of the experimental site and soil have been provided in [43,44].

\subsection{Biological Material}

Clary sage (Salvia sclarea L.), a biennial herbaceous aromatic plant species, was cultivated for two years in the TE-polluted site. Sowing took place in the early spring of 2017, with a sowing density of 300,000 seeds per hectare, using farm-scale equipment. Seeds were provided by ITEIPMAI, a French research institute. A commercial mycorrhizal inoculum, kindly provided by Premier Tech (AGTIV ${ }^{\circledR}$ Specialty Crops, PremierTech, Rivière-duLoup, QC, Canada) and containing the AMF Rhizophagus irregularis (isolate DAOM-197198, 12,000 viable spores per gram of product, $125 \mathrm{~g} / \mathrm{ha}$ ) in a powdery formulation, was also introduced during sowing, mixed directly with sage seeds.

\subsection{Experimental Design}

The experiment was carried out over two successive years (from 2017 to 2018), with an experimental design consisting of two treatments, as described below:

The two-year assessment (repeated-measures design) covered three different monitoring times (namely, the original state of the plot before sowing; the state at first sage harvest, 
year 1; the state at second sage harvest, year 2) and two treatments: non-inoculated (NI) and inoculated with the mycorrhizal inoculum (I). The surfaces dedicated to each treatment (I or NI, $2000 \mathrm{~m}^{2}$ each) were separated from each other by $2 \mathrm{~m}$-wide lanes, which were regularly weeded. The design included five replicates for each condition. It should be noted that the original state of the plot was unvegetated.

\subsection{Soil and Plant Roots Sampling Procedure}

Five soil samples were randomly collected in the early spring of 2017, at the polluted experimental site, following a stratified sampling method to ensure a maximized coverage of the experimental plot in order to assess the site's original condition before sowing. Sampling was carried out in the $0-30 \mathrm{~cm}$ surface horizon, using a manual auger. Two other sampling campaigns, totaling 10 soil samples each, were successively conducted after 21 and 66 weeks of cultivation to respectively assess the state at first and second sage harvests. All the sampling points were geo-referenced. The root systems of the three closest growing plants were collected at each of the ten sampling locations. All samples were collected over a half-day period and transported within $2 \mathrm{~h}$. After sampling, the sage roots were vigorously shaken to remove loosely attached soil (bulk), which was discarded. The careful collection of the rhizospheric soil was done using a sterile brush and spatula tip $[45,46]$. Sage roots were finally rinsed three more times with sterilized water in order to get rid of the potentially remaining soil particles before DNA extraction. Compositing was carried out using three replicates for each sampling point (either roots or rhizospheric soil). Soil and sage roots were then frozen and stored at $-20^{\circ} \mathrm{C}$ until further use.

\subsection{DNA Extractions}

\subsubsection{Soil Samples}

Genomic DNA was extracted for each sampling point in triplicate, directly from $250 \mathrm{mg}$ of soil, using a Nucleospin Soil ${ }^{\circledR}$ kit (Macherey-Nagel, Düren, Germany), according to the manufacturer's instructions. DNA quality was verified using $1 \%(w / v)$ agarose gel and measuring the 260/280 $\mathrm{nm}$ and 260/230 $\mathrm{nm}$ ratios using a SpectraMax ${ }^{\circledR}$ iD3 device (Molecular Devices LLC, Sunnyvale, CA, USA). The concentration of all samples was determined and DNA extracts were diluted to $25 \mathrm{ng} \cdot \mu \mathrm{L}^{-1}$ for further analyses. The extracted DNA was stored at $-20^{\circ} \mathrm{C}$ until further use.

\subsubsection{Plant Root Samples}

The fine roots were kept in Eppendorf tubes and frozen at $-20{ }^{\circ} \mathrm{C}$. Genomic DNA from clary sage roots was extracted in triplicate, using a method adapted from [47,48]. Briefly, sage roots were first frozen using liquid nitrogen $\left(-196^{\circ} \mathrm{C}\right)$ in a sterilized mortar and ground into fine powder. Then, $500 \mathrm{mg}$ of the ground roots were subjected to Cetyltrimethylammonium bromide (CTAB, 1.4 M NaCl' $100 \mathrm{mM}$ Tris- $\mathrm{HCl}, \mathrm{pH} 8.0 ; 20 \mathrm{mM}$ EDTA, pH 8.0; 2\% CTAB), Polyvinylpyrrolidone (PVP 1\% w/v), $\beta$-Mercaptoethanol (5\% v/v), and activated charcoal $(0.5 \% \mathrm{w} / \mathrm{v})$ extraction $\left(30 \mathrm{~min} ; 55^{\circ} \mathrm{C}\right)$. After this incubation period, a centrifugation step was carried out $(10 \mathrm{~min} ; 16,000 \mathrm{~g})$, and lysate extraction was then performed, in two successive steps, with chlorophorm:isoamylalcohol (24:1). DNA precipitation was performed in the presence of isopropanol $\left(1 \mathrm{~h}\right.$ incubation; $\left.25^{\circ} \mathrm{C}\right)$, followed by another centrifugation (10 min; $700 \mathrm{~g}$ ). The DNA pellet was then washed three times in a row, through the addition of ice-cold ethanol (70\%), and centrifuged (10 min; $900 \mathrm{~g}$ ) before air-drying at room temperature (approx. $90 \mathrm{~min} ; 20^{\circ} \mathrm{C}$ ). Finally, the DNA pellet was dissolved in $50 \mu \mathrm{L}$ of TE buffer (10 mM Tris-HCl, pH 8.0; $1.0 \mathrm{mM}$ EDTA, pH 8.0). The quality assessment of the extracted DNA, normalization to $25 \mathrm{ng} \cdot \mu \mathrm{L}^{-1}$, and storage were performed as described above. 


\subsection{PCR and Sequencing}

2.6.1. Fungal ITS

The fungal ITS region was amplified by PCR using a PCR thermal cycler (Surecycler 8800, Agilent Technologies, Les Ulis, France) with CS1 and CS2 barcoded degenerated primers as follows:

Forward primer: CS1_ITS 3 _Kyo2_F ACACTGACGACATGGTTCTACAGATGAAGAACGYAGYRAA, reverse primer: CS2_ITS 4 _Kyo3_R TACGGTAGCAGAGACTTGGTCTCTBTTVCCKCTTCACTCG, with an expected length of $327 \mathrm{bp}$ [49]. CS1 and CS2 adapters with molecular barcodes are displayed in bold.

Triplicate reactions per DNA sample were performed. The reaction mixtures $(25 \mu \mathrm{L})$ contained $5 \mu \mathrm{L}$ of Q5 (5X) reaction buffer, $3 \mu \mathrm{L}$ of Q5 (5X) High GC enhancer, $0.25 \mu \mathrm{L}$ of Q5 ${ }^{\circledR}$ High-Fidelity DNA Polymerase (New England Biolabs France, Evry, France), $0.8 \mu \mathrm{L}$ of each primer $(0.4 \mu \mathrm{M}), 1 \mu \mathrm{L}$ of dNTPs $(0.2 \mathrm{mM}), 1 \mu \mathrm{L}$ of DMSO, $1 \mu \mathrm{L}$ of Bovine Serum Albumin (BSA; $100 \mu \mathrm{g} \cdot \mathrm{mL}^{-1}$ ), and $1 \mathrm{ng}$ of DNA template. The PCR conditions were as follows: Initial denaturation at $95^{\circ} \mathrm{C}$ for $10 \mathrm{~min}$, followed by thirty-five cycles of $94{ }^{\circ} \mathrm{C}$ for $20 \mathrm{~s}, 47^{\circ} \mathrm{C}$ for $30 \mathrm{~s}$, and $72{ }^{\circ} \mathrm{C}$ for $20 \mathrm{~s}$, and a final elongation step at $72{ }^{\circ} \mathrm{C}$ for $7 \mathrm{~min}$.

\subsection{2. $18 \mathrm{~S}$ rRNA Gene of AMF}

As the previously described primers were intended for the assessment of the whole fungal community, the DNA of AMF was specifically amplified using Nested-PCR (Surecycler 8800, Agilent Technologies, Les Ulis, France) in order to obtain an improved resolution of the AMF community composition. The first PCR amplification was performed using a set of primers AML $_{1}$ (ATCAACTTTCGATGGTAGGATAGA) and AML 2 (GAACCCAAACACTTTGGTTTCC), targeting the small $18 \mathrm{~S}$ subunit of the rRNA gene, which generates amplicons of about $800 \mathrm{bp}[35,50]$. The PCR conditions were as follows: Initial denaturation at $94{ }^{\circ} \mathrm{C}$ for $3 \mathrm{~min}$, followed by 35 cycles of $94{ }^{\circ} \mathrm{C}$ for $1 \mathrm{~min}, 45^{\circ} \mathrm{C}$ for $1 \mathrm{~min}$, and $72{ }^{\circ} \mathrm{C}$ for $1 \mathrm{~min}$, and a final elongation step at $72{ }^{\circ} \mathrm{C}$ for $5 \mathrm{~min}$. PCR reactions were performed in triplicate, with a reaction volume of $25 \mu \mathrm{L}$ and conditions as follows: $5 \mu \mathrm{L}$ of Q5 (5X) reaction buffer, $0.25 \mu \mathrm{L}$ of $\mathrm{Q} 5^{\circledR}$ High-Fidelity DNA Polymerase (New England Biolabs France, Evry, France), $0.8 \mu \mathrm{L}$ of each primer $(0.4 \mu \mathrm{M}), 1 \mu \mathrm{L}$ of dNTPs $(0.2 \mathrm{mM}), 1 \mu \mathrm{L}$ of DMSO, $1 \mu \mathrm{L}$ of BSA (100 $\left.\mu \mathrm{g} \cdot \mathrm{mL}^{-1}\right)$, and $1 \mathrm{ng}$ of DNA template.

The second PCR amplification used an identical reaction mixture as described above, including $1 \mathrm{ng}$ of the first amplification as a template, with the set of primers nu-SSU-05955-F (ACACTGACGACATGGTTCTACACGGTAATTCCAGCTCCAATAG) and nu-SSU0948-3-R(TACGGTAGCAGAGACTTGGTCTTTGATTAATGAAAACATCCTTGGC) [51], complemented with CS1 and CS2 barcoded adapters (displayed in bold). The reaction conditions were as follows: Initial denaturation at $94{ }^{\circ} \mathrm{C}$ for $3 \mathrm{~min}$, followed by thirty-five cycles of $94{ }^{\circ} \mathrm{C}$ for $1 \mathrm{~min}, 58{ }^{\circ} \mathrm{C}$ for $1 \mathrm{~min}$, and $72{ }^{\circ} \mathrm{C}$ for $1 \mathrm{~min}$, and a final elongation step at $72{ }^{\circ} \mathrm{C}$ for $5 \mathrm{~min}$. This second amplification generated an amplicon of about $400 \mathrm{bp}$ in length [35].

\subsubsection{Illumina MiSeq Sequencing}

The triplicates for each PCR product ( $n=25$ for soil; $n=20$ for roots) were first indexed and then pooled together and sent for sequencing at the Genome Quebec Innovation Centre (Montreal, QC, Canada) using an Illumina MiSeq producing paired-end reads of $2 \times 300 \mathrm{bp}$ in length.

\subsection{Bioinformatic Processing}

Bioinformatic and statistical analyses were performed using the R 3.6.1 software [52]. We should note that a bioinformatic analysis was run separately for each fungal (root or soil) and AMF (root or soil) data set, as these were separately sequenced and, therefore, a specific error model for each data set was calculated. Paired-end sequences for both ITS and 18S rRNA gene data sets were filtered, denoised, dereplicated, and filtered for chimeras using the denoising pipeline DADA2 (v. 1.12), following the described procedure 
(https:/ / benjjneb.github.io/dada2/tutorial.html, accessed on 14 November 2019). At the end of the workflow, amplicon sequence variants (ASV) were inferred. Due to the highly variable length of the ITS region, which may compromise the reliability of the filtering and trimming steps, a variation of the DADA2 pipeline was used for the ITS dataset, (https://benijneb.github.io/dada2/ITS_workflow.html, accessed on 20 November 2019). A truncation tool, "Cutadapt" was used for the removal of the ITS primers prior to trimming and filtering with DADA2 [53].

Taxonomic assignment for the ITS data set was performed through the DADA2 pipeline, using the Ribosomal Database Project naïve Bayesian classifier [54]. The Unite fasta release (Unite Community, accessed on 5 November 2019) was used to assign fungal taxa from the kingdom to the genus level. Each fungal ASV was further assigned to functional groups of fungi using FUNguild [55]. For each assignment, a confidence ranking was attributed ("possible", "probable", and "highly probable"), reflecting the likelihood that a taxon belongs to a given guild, based on previous peer-reviewed data [55]. Only functional assignments with a probable or higher confidence ranking were taken into account.

For the AMF taxonomy, a two-step workflow was followed. The Silva v132 database formatted for DADA2 [56] was used as a first step to assign fungal taxa from kingdom to genus (minimum bootstrap 80) and compared to the results obtained with a nucleotide BLAST. The first step's aim was to detect and exclude ASVs identified as nonGlomeromycota at the phylum level. As a second step, a phylogenetic tree was constructed, based on reference sequences from well-identified AMF cultures, in order to support and refine the taxonomic identification of each ASV [51]. Multiple alignment using 86 consensus sequences [57] and the ASVs identified as Glomeromycota was first conducted using Kalign [58]. A maximum-likelihood tree was then calculated using RAxML v8.2.10 [59] through the CIPRES web portal [60], which provides online bioinformatic tools.

Alpha richness (Chao1) and diversity (Shannon) indices were calculated using the phyloseq R package, for both ITS and $18 \mathrm{~S}$ data sets.

\subsection{Nucleotide Sequence Accession Number}

The ITS and 18S rRNA gene sequences of the whole data set have been deposited in the NCBI Sequence Read Archive database and can be reached under the project accession number PRJNA665726.

\subsection{Statistical Analysis}

Prior to any statistical analysis, the Shapiro and Bartlett tests were conducted to assess the normality and homoscedasticity of the data, respectively. If both conditions were verified, ANOVA analysis was carried out. Otherwise, a Kruskal-Wallis non-parametric test ("kruskal.test" function in R), complemented with a post-hoc Dunn test, were used. The significance of the statistical analyses was considered at $\alpha=0.05$.

Rarefaction curves were first created using the "rarecurve" function of the Vegan package in $\mathrm{R}$, in order to verify whether the sequencing depth was adequate and reflected the original diversity or not. Based on Bray-Curtis dissimilarity, permutational multivariate analyses of variance (PERMANOVA) and principal coordinate analyses (PCoA) were conducted with the help of the Vegan package in R. PERMANOVA was run with 1000 permutations using the "adonis" function, with a constrained model for inoculation and time parameters. Venn diagrams were constructed to highlight the numbers of shared ASVs between the experimental conditions with the help of the Vegan package. Correlation heatmaps, based on the obtained Pearson's correlation matrix, were plotted using the "heatmap2" function of the gplots R package. 


\section{Results}

\subsection{Raw Sequences Bioinformatic Processing}

The 25 soil samples and 20 root samples yielded 1,558,856 and 1,403,165 fungal (ITS) raw MiSeq reads for the soil and root biotopes, respectively, while 1,553,389 and 1,193,261 reads were obtained for AMF (18S) from the soil and root biotopes, respectively. After quality filtering and chimera removal, we retained 25,241 and 29,877 fungal sequences for the soil and root biotopes, respectively. From the AMF data, 19,053 and 32,241 sequences remained from the soil and root biotopes, respectively, for community analyses. The complete procedure, with the number of sequences at each step, is shown in Table S1.

To compensate for the uneven sequencing efforts of different samples, a resampling step was performed in order to randomly select the same number of sequences per sample. The results of the rarefaction analyses showed that both data sets (ITS and 18S) tended to reach a saturation plateau (Figure S1). As such, this suggests that the sequencing depth was adequate to capture most of the fungal and AMF diversity from the rhizospheric soil and the roots of clary sage.

\subsection{Fungal and AMF $\alpha$-Diversity in Root and Soil Biotopes}

The fungal and AMF ASVs richness and $\alpha$-diversity were evaluated separately for each experimental condition (i.e., culture duration-soil before sowing, year-1, and year-2) and mycorrhizal inoculation (NI or I), and accordingly for root and soil biotopes.

According to the Chao1 index, the fungal richness in soil was stable between the soil before sowing and year 1 but significantly decreased between year 1 and year 2 for both NI and I treatments (Figure 1A). No significant difference was observed between I and NI treatments. It is noteworthy that richness measured in roots, regardless of the treatment, were similar to those obtained from soil in year 2 and, hence, were lower than those measured in soil in year 1. In addition, in roots, the fungal richness was found to be equivalent, regardless of the treatment or monitoring time. Regarding AMF richness, the results showed that it was similar in soil, regardless of the treatment or monitoring time. In roots, a significant richness increase between year 1 and year 2 was only observed for the I treatment $(p<0.05)$. However, no significant difference was observed between NI and I treatments. In addition, similar values were obtained in soil and roots, except for the I treatment in year 2 .

Regarding the diversity estimator (Shannon index) in soil, our results showed that its value was stable between the soil before sowing and year 1, then dropped between year 1 and year 2 for the total fungi (ITS) data set (Figure 1B). Similar results were observed between NI and I treatments. In roots, the fungal diversity was found to be equivalent to that measured in the soil in year 2, regardless of the treatment or monitoring time. For the AMF data set, the diversity was found to be equivalent, regardless of the biotope (soil or root), the treatment (NI or I), or the monitoring time (soil before sowing, year 1, and year 2). It is noteworthy that the highlighted trends were similar between both total fungi and AMF data sets. 


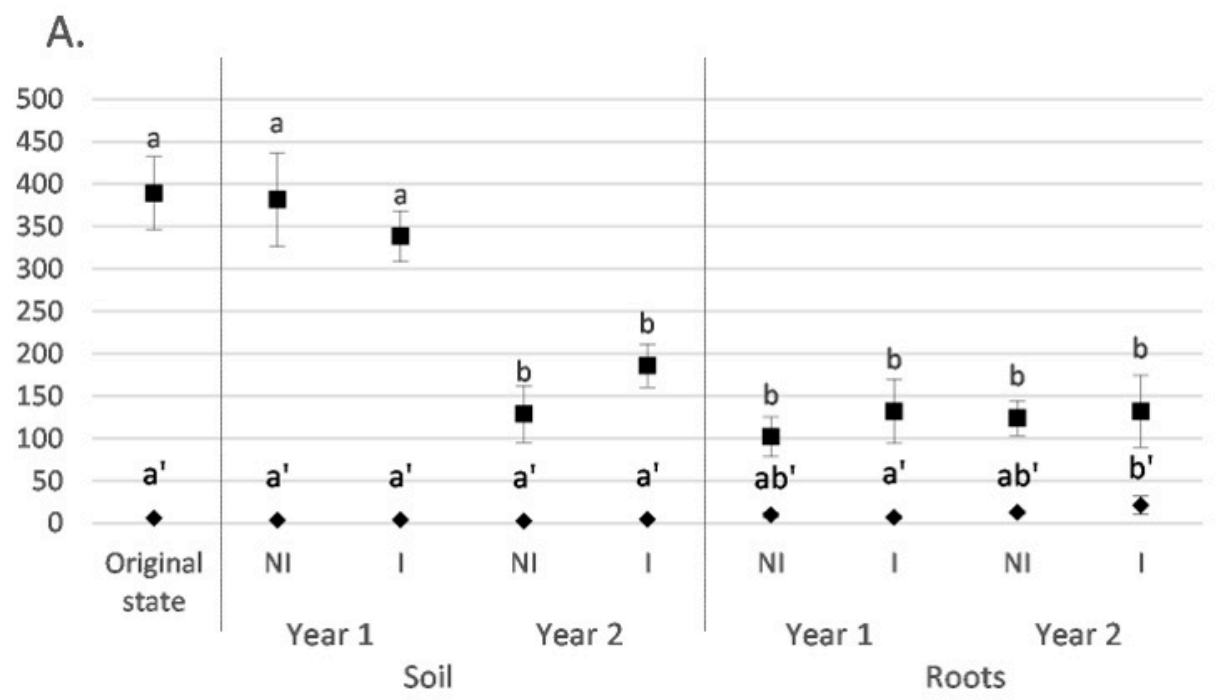

Total Fungi

B.

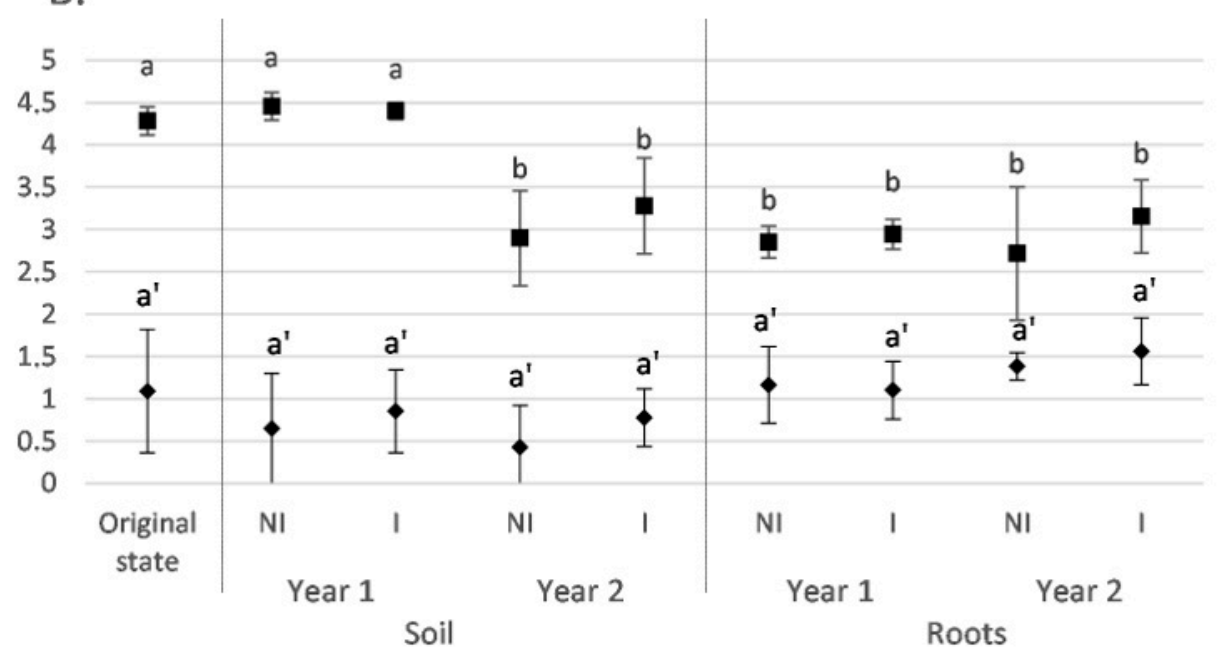

Figure 1. Richness (Chao 1 index, (A)) and diversity (Shannon, (B)) indices for the five studied conditions for soil whole fungal (ITS) and AMF (18S) communities and the four studied conditions for root whole fungal and AMF communities. Data are means $\pm \operatorname{SD}(n=5)$ for each condition. Means followed by the same letter do not differ significantly, according to the Kruskal-Wallis test complemented by Dunn post-hoc test $(\alpha=0.05)$. Lowercase letters and lowercase letters complemented with an apostrophe refer to the test performed for the Total Fungi, and AMF data sets, respectively.NI: non-inoculated; I: inoculated.

\subsection{Influence of Mycorrhizal Inoculation and Cultivation Duration on the Fungal Community Composition}

The effect of the experimental parameters-namely, mycorrhizal inoculation and cultivation duration - on soil and root fungal (ITS and 18S data sets) communities was evaluated through the use of principal coordinate analysis (PCoA), complemented with a Permutational multivariate analysis of variance (PERMANOVA). For the ITS data set, we observed a clear clustering of the fungal communities in response to the cultivation duration in both soil and root biotopes (Figure 2A,B). Specifically, the fungal communities in the soil before sowing and at year 1 were clustered together and separated from those of year-2 $(p<0.001)$. In addition, mycorrhizal inoculation distinguished the fungal communities in year 2 between I and NI treatments (Figure 2A; $p<0.05$ ). In roots, fungal communities from year 1 and year 2 were clustered separately, depicting a time effect (Figure 2B). However, no difference was observed between I and NI treatments, regardless of the year. Of the 
total variance in the data set, the first two principal components together explained $46 \%$ of the total soil fungal communities and $38.3 \%$ of the total root fungal communities.

A.
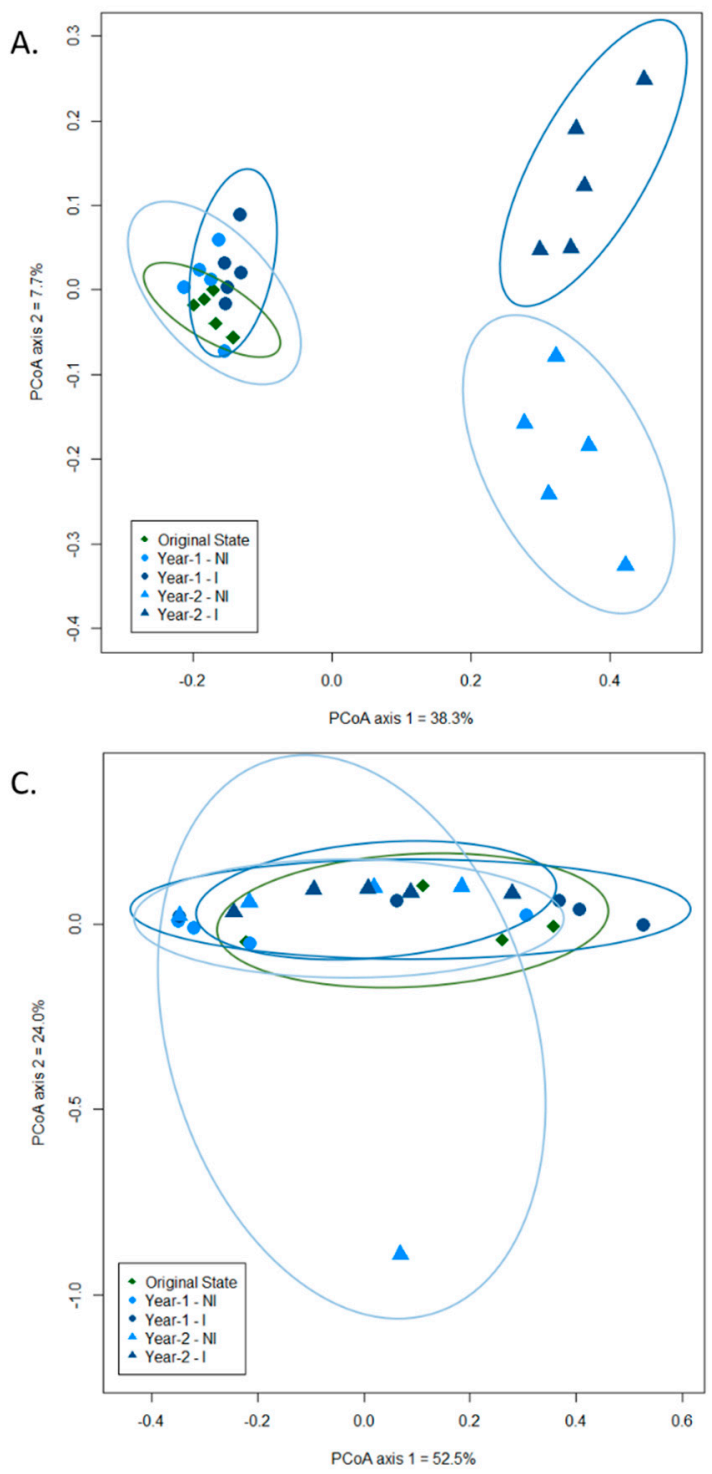

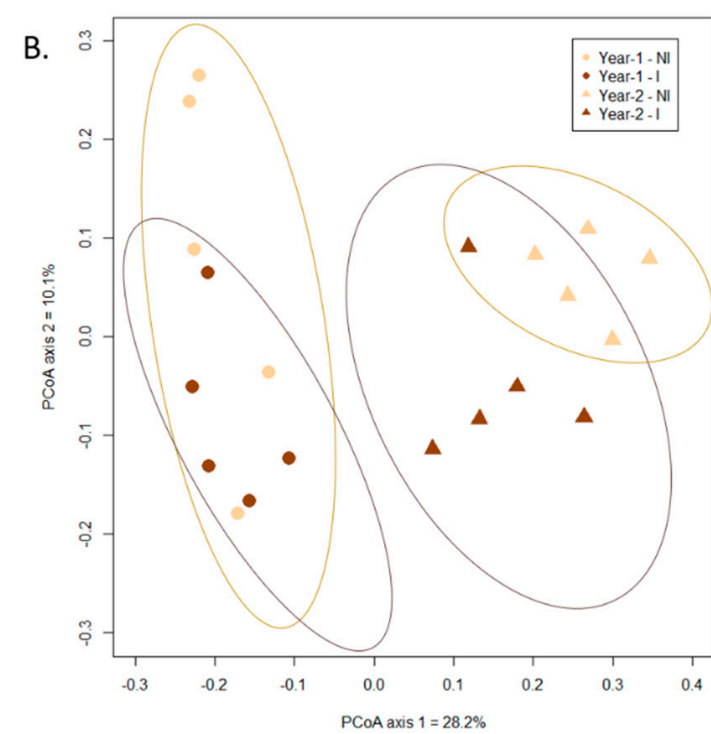

.

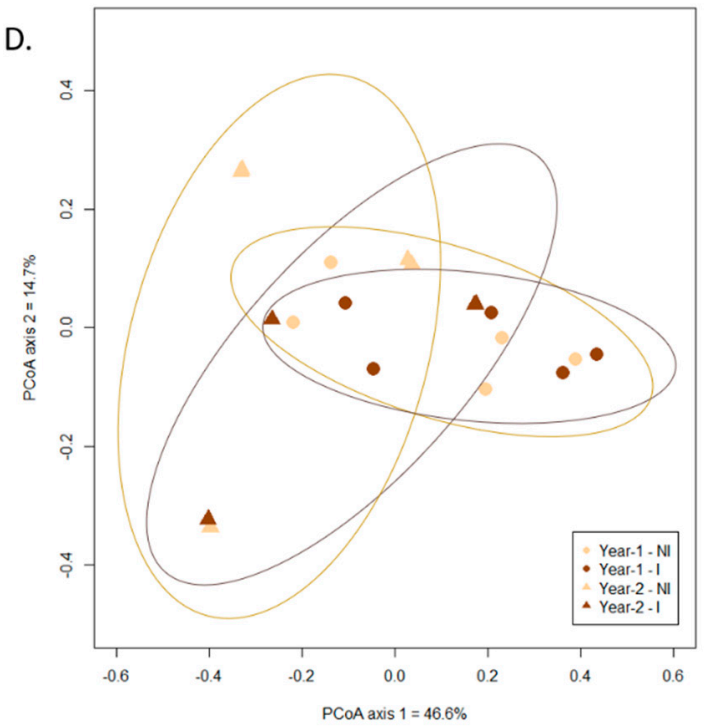

Figure 2. Principal coordinate analysis (scaling 1) based on Bray-Curtis dissimilarity for soil (A) and (C) and root (B) and (D) fungal ASVs from the ITS (A) and (B) and 18S (C) and (D) data sets in the different experimental conditions. Confidence area of ellipses $=0.95$. NI: non-inoculated; I: inoculated.

These results were confirmed by the PERMANOVA analyses, displaying significant effects of the mycorrhizal inoculation in soil $(p<0.05)$ and of the cultivation duration in both soil and root biotopes ( $p<0.001$ in both cases).

For the $18 \mathrm{~S}$ data set, the first two principal components of the PCoA ordination together explained $76.5 \%$ of the total soil AMF communities and $61.3 \%$ of the total root AMF communities (Figure 2C,D). Our PCoA results demonstrated that neither cultivation duration nor mycorrhizal inoculation significantly affected AMF communities in the clary sage rhizospheric soil (Figure 2C) or root biotopes (Figure 2D). Nonetheless, PERMANOVA highlighted a significant effect of the cultivation duration in the root $(p<0.01)$.

For the ITS data set, a total of 761, 696, 644, 206, and 343 fungal ASVs were identified in the soil before sowing, in year 1 (NI and I), and in year 2 (NI and I) treatment samples, respectively, while a total of 221,294, 214, and 251 fungal ASVs were present in the root biotope for year 1 (NI and I) and year 2 (NI and I) treatments, respectively (Figure S2A,B). 
The total number of ASVs significantly decreased by about $60 \%$ in year 2, regardless of the treatment, depicting a net shift between year 1 and year 2 . It is noteworthy that, in year 2, for the I treatment, the drop in the total number of ASVs was lower in comparison with the NI treatment (Figure S2A). In the roots, equivalent numbers of ASVs were shared between I and NI treatments and between the successive years (Figure S2B). However, higher numbers of total ASVs were highlighted for the I treatment, in comparison with the NI one, regardless of the year.

Regarding the 18 S data set, a total of $12,8,9,5$, and 11 AMF ASVs were identified in the soil before sowing, year 1 (NI and I) treatments, and year 2 (NI and I) treatments, respectively, while a total of 22, 14,21, and 52 AMF ASVs were present in the roots for year-1 (NI and I) and year-2 (NI and I) treatments, respectively (Figure S2C,D). Due to the relatively low number of AMF ASVs in the soil, there was no clear trend between the different experimental treatments (Figure S2C.). However, in the roots, there was a significant increase (of about $70 \%$ ) in terms of the number of ASVs for the I treatment between year 1 and year 2 (Figure S2D). This same trend was not observed for the NI treatment between year 1 and year 2 . In addition, there was no significant difference in year 1 between NI and I treatments, whereas the total number of AMF ASVs in the I treatment was significantly higher in year 2 , in comparison with NI.

\subsection{Taxonomic Variations in the Fungal Communities in Response to Mycorrhizal Inoculation and Cultivation Time}

The fungal diversity and the potential changes induced by the cultivation time and mycorrhizal inoculation were assessed after a taxonomic assignment at phylum, class, order, family, and genus levels. In this regard, soil fungal ASVs were assigned to 12 different phyla, while root fungal ASVs were assigned to four different ones (Figure 3A). Regardless of the experimental condition and biotope, Ascomycota was the most-represented phylum. More specifically, it represented about $70 \%$ of the total fungal ASVs in the soil before sowing and at year 1, increasing to more than $90 \%$ in year 2. Basidiomycota and Mortierellomycota were also among the most-represented phyla, especially in the soil before sowing and year 1 , but decreased in year 2 . All the other identified phyla displayed significantly lower relative abundances (below $0.5 \%$ ), regardless of the condition and the biotope. In roots, the relative abundance of Ascomycota exceeded 90\%, regardless of the condition. Basidiomycota and Mortierellomycota were also present in roots but in significantly lower proportions (ranging from 0.005 to $9.4 \%$ ). In addition to these three phyla, Glomeromycota was the only other identified fungal phylum in roots, with a relative abundance of about $0.05 \%$.

At the genus level, the dominant fungal taxa in soil were Gibellulopsis, Mortierella, Cercophora, Fusicolla, and Lasiospheris (Figure 3B). Gibellulopsis was well-represented in all samples, regardless of the experimental condition. This genus was found to be particularly dominant in year 2 in the non-inoculated treatment, with a relative abundance of $42 \%$. In addition, while most of the genera were stable under all treatments and cultivation times, some variations were observed. In particular, Mortierella abundance was about $4 \%$ in the soil before sowing then increased to $10 \%$ in year 1 and dropped to lower than $0.1 \%$ in year 2, regardless of the treatment. Furthermore, Plectosphaerella and Botrytis were poorly represented in the soil before sowing and at year 1 , with relative abundances lower than $1 \%$, but significantly increased in year 2 (up to 13\%). Finally, Acrostalagmus was specifically present in the NI treatment at year 2 . 
A.

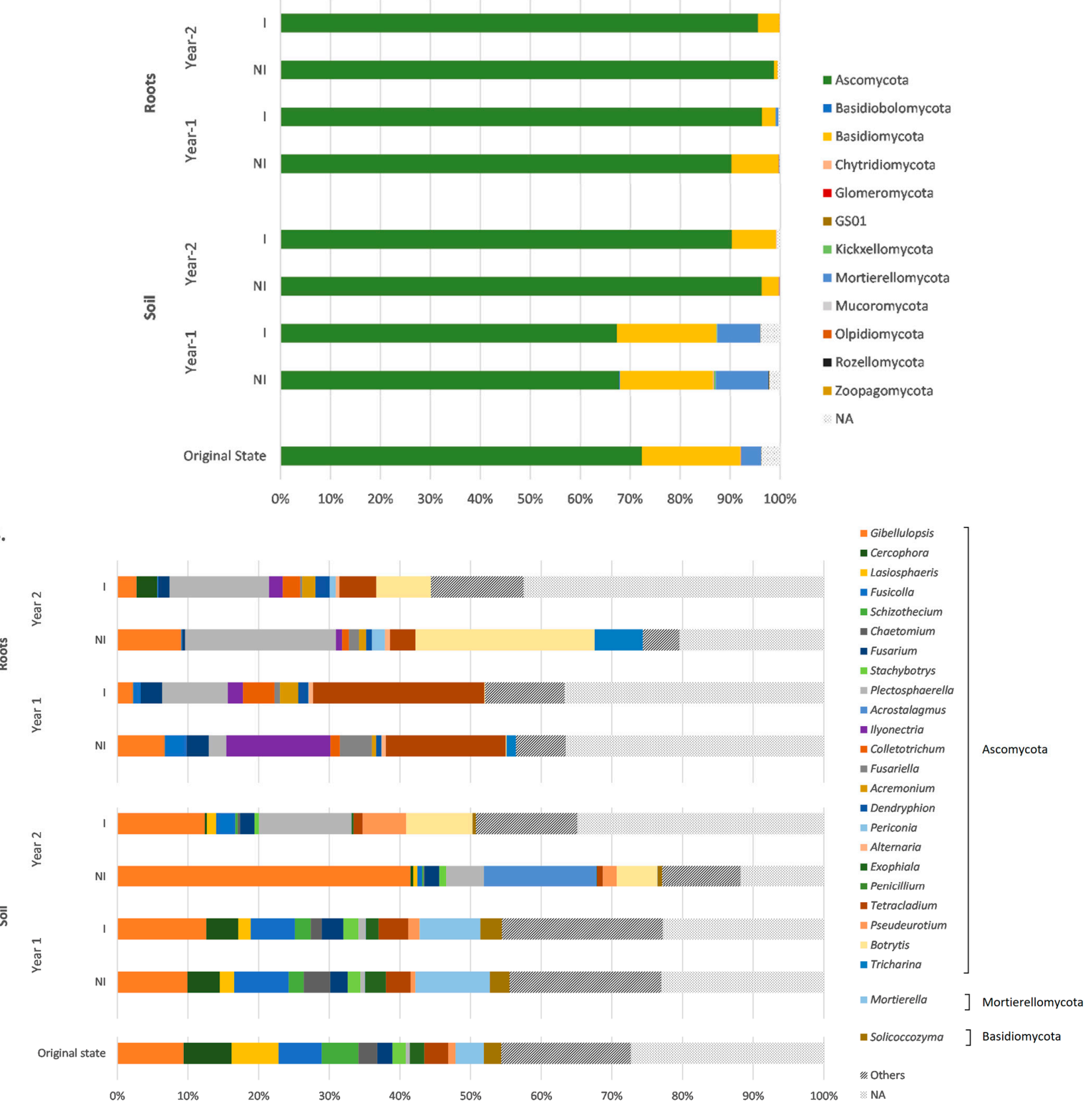

B.

Figure 3. Relative abundances of major phyla (A) and genera (B) of the fungal ITS rRNA gene data set, according to the different experimental conditions for both root and soil biotopes. The genera were grouped by phylum, and those with a relative abundance lower than $0.5 \%$ were gathered in the "Others" group. NI: non-inoculated; I: inoculated; NA: non-assigned.

In roots, similar to the soil biotope, Gibellulopsis was among the most-represented genera, but along with Tetracladium, Plectosphaerella, and Botrytis (Figure 3B). The proportions of the dominant genera were significantly different, especially between the two sampling times (year 1 and year 2). In particular, Tetracladium was extensively represented in year 1 and decreased in year 2, with abundances of $17 \%, 24 \%, 4 \%$, and $5 \%$ for year 1 and year $2 \mathrm{NI}$ and I treatments, respectively $(p<0.05)$. Conversely, Plectosphaerella and Botrytis were poorly represented in year 1 , but significantly rose in year 2 samples, with respective increases of about $66 \%$ and $99 \%(p<0.01)$. It should be noted that a relatively 
high number of fungal ASVs were not assigned to genera, as depicted by the proportion of "Non-Assigned" ("NA") ranging from $12 \%$ to $40 \%$.

\subsection{Taxonomic Identification of ASVs Belonging to the AMF $18 S$ rRNA Gene Data Set}

The results of the phylogenetic analysis (Figure S3) allowed for the assignment of 65 out of the 81 identified ASVs (total AMF data) from the 18S rRNA gene data set to eight genera, namely, Acaulospora, Ambispora, Archeospora, Claroideoglomus, Funneliformis, Glomus, Rhizophagus, and Scutellospora. Sixteen ASVs could not be assigned at the genus level with a sufficient confidence level, as they did not cluster with any of the consensus sequences. The 65 other ASVs represented six different families (Acaulosporaceae, Ambisporaceae, Archeosporaceae, Claroideoglomeraceae, Gigasporaceae, and Glomeraceae). Notably, $39(60 \%)$ out of the 65 ASVs were assigned to the Glomeraceae family and, among them, the genera Funneliformis and Glomus were the two most-represented ones, with 19 and 17 members, respectively. Only three ASVs belonged to the genus Rhizophagus. It is noteworthy that, among the 65 ASVs assigned at the genus level, four of them were present in both root and soil biotopes.

A heatmap representation was consecutively drawn, based on the relative abundance of the 10 and 15 most-represented AMF ASVs in the rhizospheric soil and the root biotopes, respectively (Figure 4).

A. Soil biotope

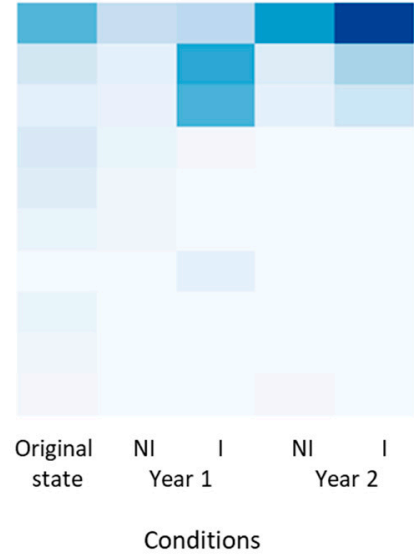

B. Root biotope

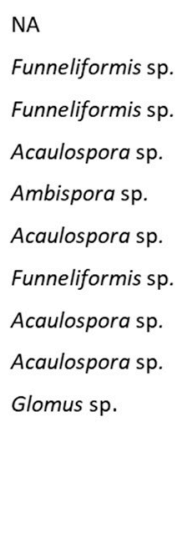

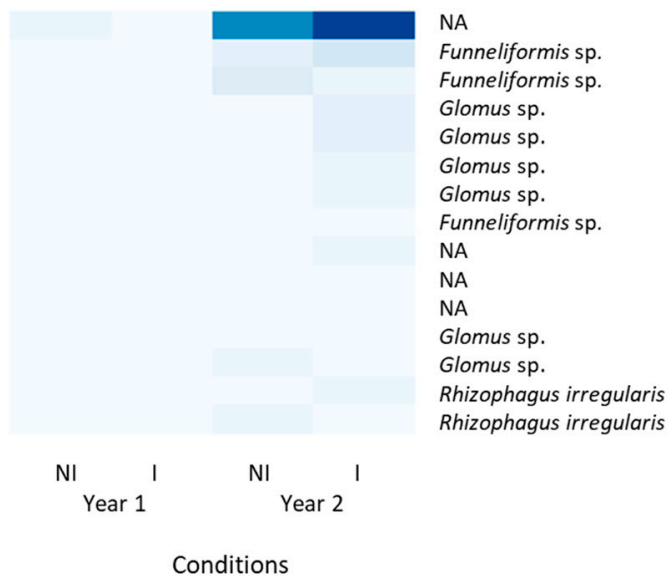

Funneliformis sp. Funneliformis sp. Glomus sp. Funneliformis NA Glomus sp. Glomus sp. Rhizophagus irregularis Rhizophagus irregularis

Conditions

Figure 4. Heatmap representation based on the abundance of the 10 and 15 most-represented ASVs from the $18 \mathrm{~S}$ rRNA gene data set identified in the rhizospheric soil (A) and $\operatorname{root}(\mathbf{B})$ biotopes, respectively. NI: non-inoculated; I: inoculated; NA: non-assigned.

This analysis revealed that the most abundant ASV in both soil and roots, which was identical, was present in the initial soil state but significantly decreased in year 1 and, similarly, was scarcely represented in the year 1 root biotope. However, it consistently increased and was mostly represented in both biotopes in year 2 . Specifically, in soil, the two most abundant ASVs attributed to the Funneliformis genus were particularly abundant in the inoculated treatment, both in year 1 and year 2, but were scarcely represented otherwise. Conversely, ASVs attributed to Acaulospora spp. were more abundant in the initial soil state and decreased in year 1 and year 2. Funneliformis spp. were also present in rootsspecifically, in year 2-with no distinction between I and NI treatments. Furthermore, ASVs identified as Rhizophagus irregularis were present in the root biotope in both I and NI treatments in year 2. From an overall perspective, it is noteworthy that ASVs were more abundant in year 2, especially in the inoculated treatment. 


\subsection{Prediction of Functional Assignments of ASVs}

Among the 1239 and 569 fungal ASVs recorded in the soil and root biotopes for the ITS data set, respectively, $48 \%$ and $53 \%$ were successfully assigned to a functional guild with at least a "probable" confidence ranking, using FUNGuild [55]. This functional assignment revealed a majority of saprotrophic fungi-up to $54 \%$ of the total abundanceas well as variable proportions of putative fungal plant pathogens, ranging from $19 \%$ up to $60 \%$ (Figure 5). It is noteworthy that the relative abundance of plant pathogenic fungi significantly increased in the soil in year $2(p<0.05)$ in comparison with the soil before sowing and at year 1 ; however, in roots, no significant difference was observed between year 1 and year 2. Conversely, the proportions of saprotrophic fungi decreased over time in both biotopes and were at the lowest level during year 2. Besides, endophytic fungi were less represented, especially in soil, with relative abundances close to $0 \%$, except for the NI treatment at year 2; whereas, in roots, the relative abundances ranged from $3 \%-10 \%$, regardless of the treatment and the monitoring time. In addition, AMF was present but only accounted for less than $0.05 \%$ of the total abundance, as only four and five ASVs were assigned to AMF for soil and root biotopes, respectively.

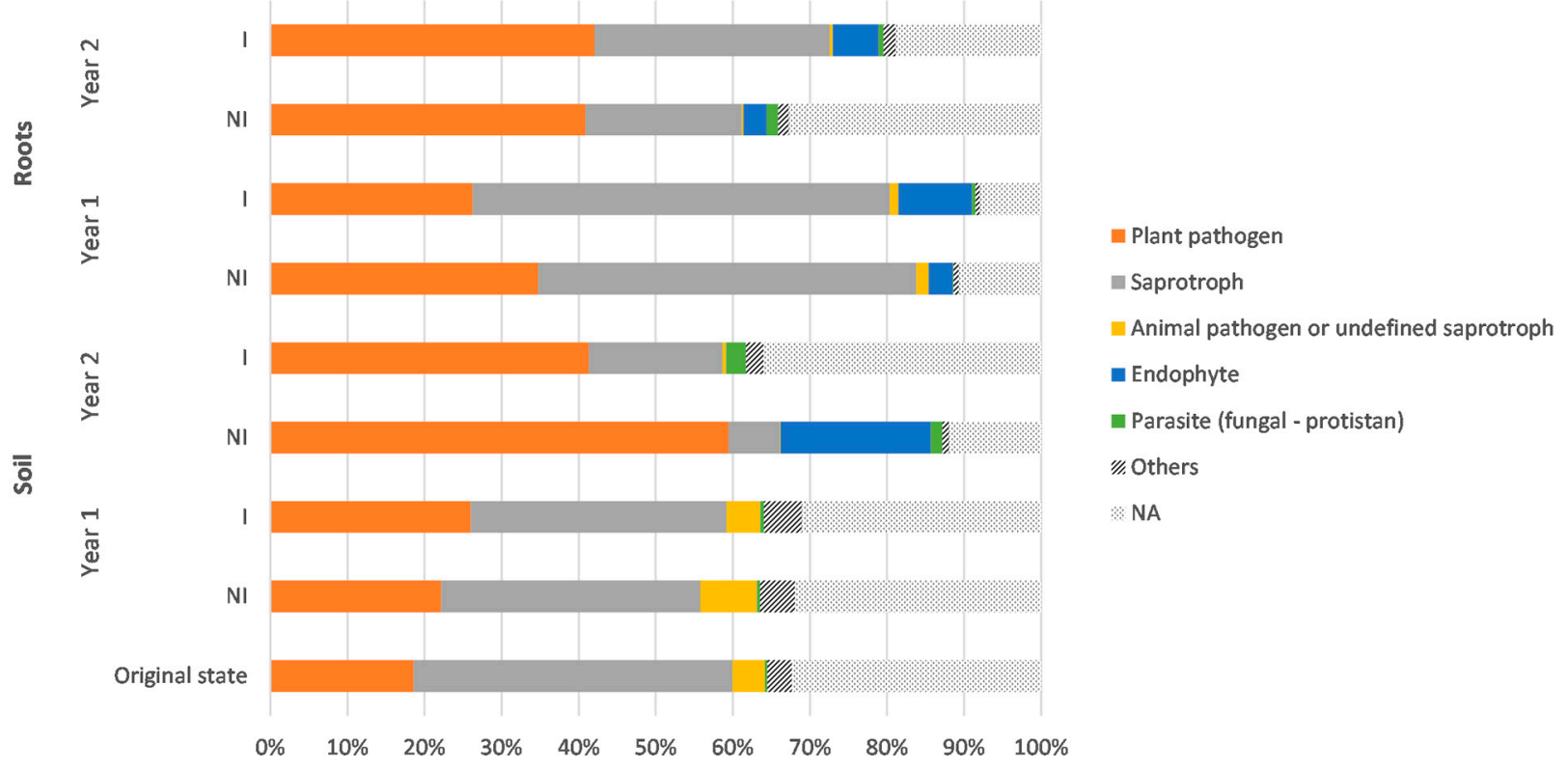

Figure 5. Relative abundances of major fungal functional groups of the ITS rRNA gene data set, according to the different experimental conditions for both root and soil biotopes. The guilds with a relative abundance lower than $0.5 \%$ are gathered in the "Others" group. NI: non-inoculated; I: inoculated; NA: non-assigned.

In addition to the functional assignments, we identified potential correlations between the 20 most abundant ASVs, sage dry weight, and root arbuscular mycorrhizal rates using a heatmap based on Pearson's correlation coefficients between the 20 most abundant ASVs and sage biomass and root arbuscular mycorrhizal rates were drawn, so as to identify potential correlations between each other, in both the rhizospheric soil and root biotopes (Figure 6). 
A. Soil biotope
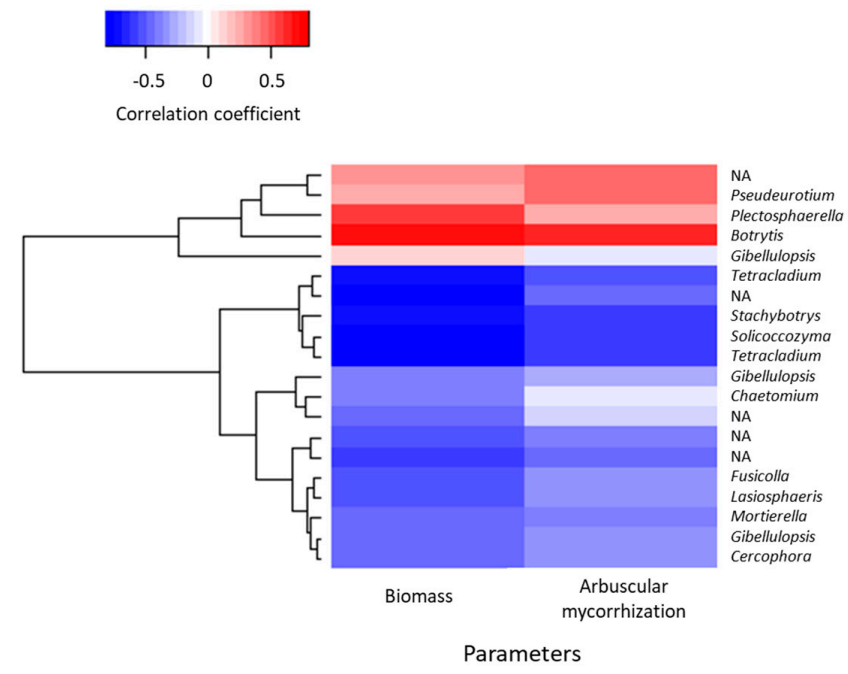

B. Root biotope
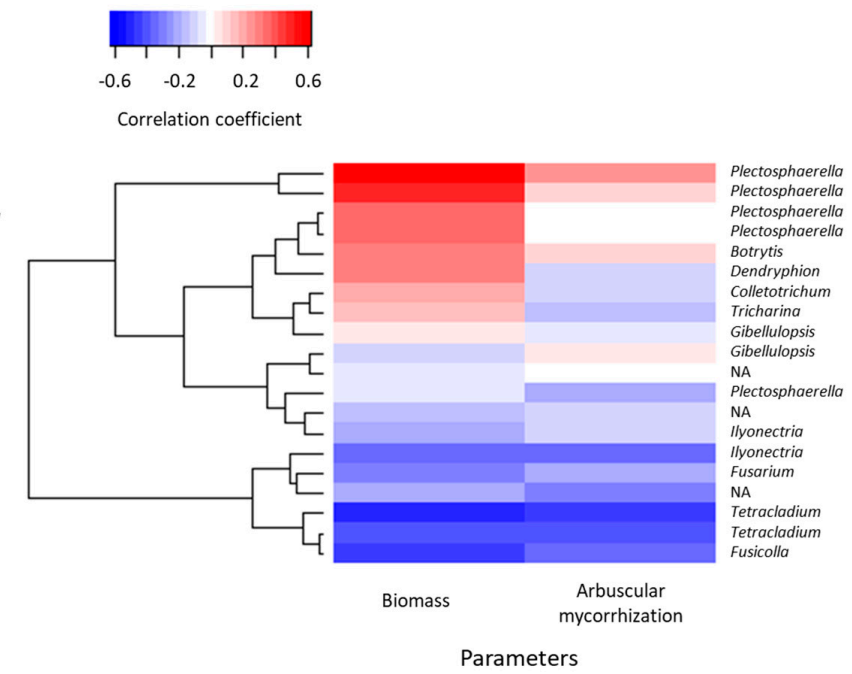

Figure 6. Heatmap representation based on the correlation coefficients between clary sage biomass (dry weight) or arbuscular mycorrhization and the 20 most represented fungal ASVs from the ITS data set in soil (A) and root (B) biotopes. They respectively belong to 12 and 10 fungal genera. NA: non-assigned.

These correlation coefficients ranged from -0.88 to 0.69 and from -0.55 to 0.63 for the soil and root biotopes, respectively. Botrytis was the fungal genus in soil displaying the highest positive correlation coefficients, regarding both sage dry weight and root arbuscular mycorrhizal rates, while Pseudeurotium also displayed a high correlation with arbuscular root mycorrhization (Figure 6A). Similarly, in roots, the Botrytis genus was strongly and positively correlated to sage biomass, as well as Plectosphaerella (Figure 6B). However, regarding arbuscular mycorrhization, the fungal ASVs displayed either low or null correlation coefficients. Conversely, Tetracladium, Stachybotrys, and Solicoccozyma displayed the highest negative correlations in soil, regarding both plant biomass and root mycorrhization, while Tetracladium was strongly but negatively correlated to both parameters in the root biotope (Figure 6B).

For the AMF $18 \mathrm{~S}$ rRNA gene data set, the correlation coefficients ranged from -0.35 to 0.30 and from 0.19 to 0.76 for the soil and root biotopes, respectively. In soil, despite the positive correlation coefficients measured for the most abundant ASVs, no clear correlation was established between the 10 most represented ASVs and plant biomass and arbuscular mycorrhization, given the low values determined for the correlation coefficients (Figure S4). Conversely, in the roots, all the ASVs displayed positive correlation coefficients. In particular, ASVs assigned to Funneliformis spp. displayed similar behavior, with respect to plant dry weight, with correlation coefficients equal to or slightly above 0.52 , depicting a correlation between each other (Figure S4). Similarly, regarding arbuscular mycorrhization, Glomus spp. displayed a positive correlation coefficients with values of about 0.55.

\section{Discussion}

Clary sage has been evaluated as part of a phytomanagement assay aimed at cultivating the aromatic plant on a TE-polluted soil and producing essential oils from the biomass, intended for use as potential biopesticides [44]. However, whereas the impact of this aromatic plant species on the soil bacterial microbiome has been investigated [43], no data are available on its effect on the fungal microbiome. Thus, under field conditions, the effects of clary sage cultivation and mycorrhizal inoculation on the total fungal community composition were determined, with a particular focus on AMF community composition in rhizospheric soil and root biotopes. 


\subsection{Ascomycota Phylum Dominates the Fungal Community in an Aged TE-Polluted Soil before Clary Sage Cultivation}

Our results showed that Ascomycota and, to a lesser extent, Basidiomycota and Mortierellomycota were the dominant fungal phyla in our in situ experimental conditions-namely, TE-polluted soil—before clary sage sowing. Notably, Ascomycota and Basidiomycota were predominant, as they accounted for more than $90 \%$ of the relative abundance together. This observation is consistent with recently published studies carried out in both agricultural or aged TE-polluted soils $[7,14,17,39,61-63]$. Ascomycota has, in particular, been depicted as the prevalent fungal phylum in various polluted or unpolluted environments due to their diversity in terms of metabolic capacities, owing to the wide variety of enzymes they produce $[7,14,63]$. They have, for instance, been reported as key decomposers of crop residues in agricultural soils $[14,64]$. Interestingly, among the members of Ascomycota and Basidiomycota, many have been shown to display a strong tolerance to TE, even in highly polluted conditions $[6,14,62,65]$. In these particular environmental conditions, some fungal communities have, indeed, exhibited a capacity to adapt over time and to develop a tolerance to TE $[13,17]$. In the case of Ascomycota and Basidiomycota, previous reports have pointed to an induction of the expression of genes coding for metallothionein or phytochelatin synthase, which are involved in fungal cell protection against harmful TE effects [66-68]. Regarding the fungal diversity in the TE-polluted site, it appeared similar to (or even slightly higher than) previous results published elsewhere in the literature, considering revegetated or agricultural TE-polluted soils, whatever the richness or diversity index $[3,7,16,17,69]$. This could notably be explained by the water $\mathrm{pH}$ being close to neutral and a soil organic matter content which can be considered as slightly higher than average, in comparison with reference indicators, in our experimental conditions. These parameters have, in fact, been demonstrated as key drivers for the richness and diversity of fungi in soils [6]. Interestingly, 12 ASVs identified as belonging to the phylum Glomeromycota and split among four different AMF families were also detected in the TE-polluted soil before clary sage sowing. Notably, a predominance of Acaulosporaceae and Glomeraceae was found, in accordance with previously published results on TE-polluted soils, which could be explained by their better adaptation to stressful environments, such as excessive amounts of TEs [70,71].

\subsection{Clary Sage Significantly Shaped the Rhizosphere Fungal Community over its Life Cycle}

The results from the PERMANOVA and PCoA analyses indicated the temporal variability of the fungal communities in both rhizospheric soil and root biotopes with high significance $(p<0.001)$ following sage growth. Regarding the diversity indices, similar results were obtained between the soil before sage sowing and the soil sampled before the harvest at year-1. Our results also demonstrated a significant drop, in terms of both richness and diversity, between year 1 and year 2; especially in soil. The same trend was observed for ASV numbers, with a clear decrease between year 1 and year 2. Besides this decrease observed in the rhizospheric soil between year 1 and year 2, a shift should also be highlighted in the roots, depicted by stable richness and diversity indices over time, but which showed changes in terms of relative abundances of fungi. Interestingly, our results suggest that the fungal communities in the rhizospheric soil and in the roots of the cultivated plant tend to become similar over time. Notably, after two years of cultivation, the fungal richness and diversity were found to be equivalent in the rhizospheric soil and in the roots of clary sage, and a similar pattern was observed between the two biotopes at the phylum level, which is consistent with the literature, as it is well-known that fungi associated with the roots are recruited into the surrounding soil community [72]. In a previous related study, the bacterial microbiota of the same aromatic plant was explored [43]. However, this trend was substantially less pronounced in the case of bacterial communities and could suggest that fungal communities are more sensitive to biotic and abiotic factors. Notably, it has previously been reported that organic matter availability was one of the key drivers of the fungal communities' composition [17]. Furthermore, despite significant differences 
in relative abundances at the genus level, it appears that the pattern was clearly identical between the state before sowing and at year 1 in soil and differs in year 2, becoming more similar to what was observed in the roots. Notably, several fungal genera, such as Botrytis or Plectosphaerella, which were very poorly represented in the soil before sowing and at year 1 simultaneously increased in year 2 , in both root and rhizospheric soil biotopes, which was expected, as both genera are necrotrophic plant pathogens [73,74].

It has been well-described in the literature that, although the impact of vegetation on soil microbial communities depends on both the growing season and the plant species $[10,17,39]$, fungal diversity usually decreases in the rhizospheric soil, in comparison with the bulk (loosely associated with the roots) or unplanted soil [75]. This fact is notably attributable to the selective pressure exerted by plant root exudates on the fungal communities; even more so in the vicinity of the root, the rhizosphere $[17,38,39,63]$. First, plant root exudates may support the growth of rhizosphere microbial communities by providing carbohydrates that act as carbon and energy sources for microbial growth $[63,76,77]$. However, particularly in the case of aromatic plants, such consistent shifts in the fungal communities have been suggested to be bound to the release of various aromatic compounds in their rhizosphere, which exert antifungal activities $[2,63,78]$. Notably, the involvement of various mono- and sesquiterpenes, such as limonene or menthol, has been postulated [2,63]. This trait has been well-documented for various aromatic plant species, such as Eucalyptus spp., Artemisa annua, and Ocimum basilicum, or from the Lamiaceae family, such as Mentha arvensis $[2,63,77]$, but remains unknown for clary sage. Nonetheless, the antifungal activity of clary sage EO and of its major compounds-namely, linalool and linalyl acetate-has repeatedly been demonstrated $[28,29,79,80]$. In particular, their activity against some fungal genera, which in the present work have been highlighted as significantly decreasing over time, such as Chaetomium or Fusarium, has previously been established $[29,79,80]$. Regarding the other fungal genera for which the biggest decreases have been observed, such as Cercophora or Tetracladium, they are saprotrophic and not phytopathogenic fungi and, as such, might not have been subject to antifungal assessment. One should note that clary sage, as depicted through the previously published results, consistently grows in the second year of cultivation, corresponding to the best harvest year for EO [24,43]. In that regard, the drastic shift observed between year 1 and year 2 could be due to the release of aromatic compounds into the rhizosphere produced in high amounts in that period. Nonetheless, the influence of environmental factors (e.g., soil physico-chemical properties, nutrient availability, and so on) on the fungal community composition has previously been discussed [6,17] and, thus, should not be neglected.

The results of the functional assignment revealed a majority of saprotrophic and plant pathogenic taxa (up to $80 \%$ ), whereas endophyte and symbiotic taxa were poorly represented in both rhizospheric soil and root biotopes. This goes along with previous findings, reporting a dominance of fungal guilds attributed to pathogens and saprotrophs, accounting for up to $90 \%$ of the community $[76,81]$. On another note, the proportion of saprotrophic taxa decreased over time, replaced by fungal genera known as plant pathogens, such as Gibellulopsis, Plectosphaerella, or Botrytis, especially between year 1 and year 2. The former was not too surprising, as mono-cropping often results in modifications in the soil microbial abundance and diversity, and usually in an increase in plant pathogenic microorganisms in soil $[76,81,82]$. Moreover, no fungicidal intervention was carried out during this field trial, which could worsen the previously described traits, as well as potentially increasing the competition between endophytic and pathogenic fungi. Nonetheless, it should be noted that fungal genera pathogenic to plants, such as Fusarium, Gibellulopsis, or Botrytis, even though they have a wide range of host plants, could be harmless for clary sage. Notably, regarding the correlation heatmaps, most of the strong positive correlations between sage biomass or root mycorrhizal rates have been brought to light with potentially phytopathogenic genera, which — to the best of our knowledge-have not been identified as pathogens towards clary sage. 


\subsection{Mycorrhizal Inoculation Shaped the Rhizosphere Fungal Community and Could Favor the Establishment of the Mycorrhizal Symbiosis}

Under our experimental conditions, inoculation clearly shaped the soil fungal communities. In fact, a clear clustering in year 2 between I and NI treatments was highlighted by the PERMANOVA analysis $(p<0.05)$ and observed in the PCoA ordination. It, however, did not significantly influence the root fungal community. In the same way, similar diversity and richness indices were determined between I and NI treatments, regardless of the monitoring time and biotope. As previously highlighted, the root exudation of carbon compounds may significantly affect the abundance of soil fungi [39]. Moreover, in the presence of mycorrhizal symbiosis, the host-plant metabolism has been found to be modified, which may result in variations of the root exudation pattern [12,32]. Thus, the stimulation or regulation of specific fungal communities through the release of carbonated or chemical compounds by the plants colonized by AMF is likely to occur and, hence, shape the fungal communities [32,63]. Likewise, the direct release of compounds by the AMF hyphae can result in a shift of the associated fungal communities. Therefore, it not surprising to observe an effect of mycorrhizal inoculation on soil fungal community composition. In particular, some fungal taxa belonging to Ascomycota, such as Nectria or Leptosphaeria genera, were previously established as being associated with AMF mycelia, which could go along with the prevalence of Ascomycota observed in our experimental conditions [38,83,84]. It should be noted that in comparison with the bacterial microbiota, where no significant effect of the inoculation was evidenced [43], a higher response of the fungal communities to exogenous mycorrhizal inoculation has been demonstrated in the present work. This goes along with previous studies, highlighting a more pronounced response of the fungal communities to both biotic and abiotic factors $[17,85,86]$.

It is also noteworthy that the decrease, in terms of both ASV number and fungal richness and diversity, observed in soil between year- 1 and year- 2 was also less pronounced under mycorrhizal inoculation. This may support the idea that, in the presence of the mycorrhizal symbiosis, the host plant and the associated microbial communities could be more resilient regarding both biotic and abiotic stresses [87,88].

In addition, it has previously been suggested that AMF inoculation could result in increased competition between AMF communities (native and exogenous) and could lead to limited efficiency or to a suppression of the mycorrhizal symbiosis establishment and functioning $[9,36]$. In fact, as has been highlighted in another related publication, the establishment of mycorrhizal symbiosis under the same experimental conditions was successful, while a significant progression of the mycorrhizal rates in response to exogenous AMF inoculation during the second year of cultivation was assessed [43]. However, regarding plant growth in spite of the consistent clary sage growth in TE-polluted conditions, similar results were obtained between I and NI treatments [43]. Given the fact that clary sage is considered a xerophytic plant species and requires low nutrient supplies, its nutrient requirements were probably met in our experimental conditions, considering the soil's physico-chemical properties [24,89-91].

Besides, in our case, no such exclusion of native AMF was visible. In fact, the introduced inoculum contained R. irregularis, while the most abundant ASVs present in both the roots and rhizospheric soil of the inoculated plants were identified as belonging to AMF genera such as Glomus or Funneliformis. In that regard, it is not clear whether the root colonization was due to the presence of the introduced mycorrhizal inoculant or to the native AMF present in the TE-polluted site. In particular, it should be noted that, even though during the second year of cultivation, ASVs identified as R. irregularis were detected with low abundance in clary sage roots, it could be a different strain than the inoculated isolate. In addition, the question arises whether the mycorrhizal symbiosis was functional or not, as the clary sage was successfully colonized by AMF. In that regard, monitoring the expression of, for instance, phosphate transporter genes (e.g., MTPT4, LEPT1, or STPT3), which are often pointed out as markers of symbiosis functioning [92-94], could help in addressing this issue. 


\subsection{The AMF Community Changed over Time under Clary Sage Cultivation, but was Not Altered by Exogenous Mycorrhizal Inoculation}

It should first be noted that a very limited proportion $(<0.5 \%)$ of the identified fungal ASVs using the primers targeting the ITS region were attributed to the Glomeromycota phylum, which demonstrates that ITS primers are not appropriate for determining AMF diversity. Thus, the use of specific primer pairs targeting the $18 \mathrm{~S}$ rRNA gene (SSU) appeared to increase the accuracy of AMF species detection and identification.

No significant effect of the mycorrhizal inoculation, as an explanatory parameter of the community composition, was highlighted, regardless of the biotope. A similar result has previously been demonstrated, using the same mycorrhizal inoculant as in the present work under unpolluted field conditions, where the authors suggested a co-evolution of the AMF community in the presence of $R$. irregularis [35]. However, in their experimental conditions, $R$. irregularis was naturally present in the soil, which was not the case in our TE-polluted site. In fact, contrasting results regarding the effects of AMF inoculation on the native AMF community have been brought forward, depicting a context-dependent explanation, particularly in stressful or disturbed conditions [95]. As previously mentioned, in our case, the introduction of the mycorrhizal inoculant did not result in a complete replacement or modification of the native AMF community and, hence, may not have resulted in drastic community changes.

However, interestingly our results demonstrated that clary sage cultivation significantly shaped the AMF community in the plant roots $(p<0.01)$. Our findings also support the same trend as previously reported, namely, the prevalence of the AMF taxa Glomeraceae and a higher number of AMF ASVs identified in roots specific to this biotope [52,96,97]. This was notably explained by a lower AMF biomass in soil—even in the rhizospherecompared to that in root tissues, depicting the importance of screening both root and soil biotopes [52,97]. Remarkably, 69 distinct AMF ASVs belonging to 12 AMF genera were identified in our conditions, with a prevalence of Funneliformis and Glomus genera. Hence, in spite of TE pollution and past agricultural practices, which have been demonstrated to be key drivers of the microbial community composition, a relatively high number of AMF species were detected in our TE-polluted site $[16,98,99]$. This prevalence, in terms of relative abundance of native AMF species, could even suggest a long-term adaptation of these species to the TE-polluted context, which could hence be more suited to surviving and colonizing plant roots in comparison with the exogenous species. Furthermore, while the effects of the AMF community on plant diversity have been well-covered, the reverse effect of plant identity on the AMF community composition and temporal evolution has been less explored [100]. Nonetheless, several reports have pointed out the influence of the host plant on the composition of the AMF community, especially in the roots [100-102]. Notably, our results support a strong temporal shift. This trend is in accordance with previous reports, as the AMF ASVs present in the newly germinated seedlings were almost entirely replaced the following year by previously scarcely represented ones [101]. In addition, during the second year of cultivation, the abundance of aromatic compounds in the rhizosphere of clary sage could have an antifungal effect and hence exert selective pressure on the AMF community composition. The trend is similar to that previously observed for the fungal community.

\section{Conclusions}

The main purposes of this field study were to analyze the fungal community composition in the rhizosphere of clary sage cultivated on a TE-polluted soil in the presence of an introduced commercial mycorrhizal inoculum and to monitor their temporal evolution over a two-year cultivation cycle, starting from unvegetated soil.

Our results indicated that both clary sage cultivation and mycorrhizal inoculation significantly shaped the fungal communities in the aromatic plant's rhizosphere. Notably, it is believed that the cultivation of aromatic plants, such as clary sage, which release root exudates and, in particular, aromatic compounds in their rhizosphere, may be responsible 
for the temporal evolution of rhizospheric fungal communities, along with environmental and edaphic parameters. Furthermore, besides shaping fungal communities, the introduction of an exogenous mycorrhizal inoculum could favor the in situ colonization of clary sage roots by AMF; however, it was not clear whether the introduction of this inoculum was directly responsible for the root colonization or if it exerted a stimulating effect on the native AMF community. Hence, one of our future prospects is the specific monitoring of the introduced inoculum isolate, as developed by [103].

Our findings also showed the prevalence of Ascomycota and Basidiomycota in the TEpolluted soil, which have been previously demonstrated to withstand the presence of TE in soils. In addition, given the number of identified AMF species in our TE-polluted site, our data suggest that quite a few AMF species could be further isolated. Notably, if it is well-known that AMF can bear the presence of TE in soils and contribute to their immobilization, their specific response to increasing levels of TE could be relevant to investigating, in view of future potential applications as part of phytomanagement approaches. Further investigations are also required regarding the long-term evolution of the fungal communities. In fact, if the ecosystem functioning may not be affected or in a positive way in response to aromatic plant cultivation and mycorrhizal inoculation, owing to microbial function redundancy, it might also result in important functional losses. Thus, a long-term assessment of structural and functional evolution over time could be a useful tool for assessing and ensuring both the success of phytomanagement and ecosystem functioning.

Supplementary Materials: The following are available online at https: / www.mdpi.com/article / 10.3390/microorganisms9061333/s1, Table S1. Descriptive results of Illumina MiSeq sequencing, followed by the step-by-step bioinformatic processing, for the fungal ITS and 18S rRNA genes datasets; Figure S1. Rarefaction curves obtained for the ITS marker (fungi - A. and B.) and for the $18 \mathrm{~S}$ rRNA gene (AMF - C. and D.), for the soil (A. and C.) and root (C. and D.) biotopes, involving respectively 25 and 20 samples; Figure S2. Venn diagrams showing the overlap of the fungal (ITS dataset - a. and b. and $18 \mathrm{~S}$ dataset $-\mathrm{c}$. and d.) community overtime for soil (A. and C.) and root (B. and D.) biotopes. These diagrams display the number of total (out of the shapes), specific and shared ASVs. The total numbers of fungal ASVs for the ITS and 18S datasets are respectively 1239 and 20 in soil and 569 and 61 in roots. NI: non-inoculated; I: inoculated; Figure S3. RaxML phylogenetic tree showing the taxonomic assignment of each $18 \mathrm{~S}$ ASVs to the genus level. The scale represents the branch length corresponding to the expected number of substitutions per site. ASV-R: indicates AMF ASVs identified in the roots; ASV-S: indicates AMF ASVs identified in the rhizospheric soil; Figure S4. Heatmap representation based on the correlation coefficients between clary sage height or arbuscular mycorrhization and the 10 most represented ASVs from the $18 \mathrm{~S}$ rRNA gene dataset in soil (A.) and root (B.) biotopes respectively. NA: non-assigned taxonomy.

Author Contributions: Conceptualization-methodology—validation, R.R., J.F., M.H., and A.L.-H.S.; writing—original draft preparation, R.R.; writing—review and editing, R.R., J.F., M.H., and A.L.-H.S.; supervision, A.L.-H.S. All authors have read and agreed to the published version of the manuscript.

Funding: This work was supported by l'Agence De l'Environnement et de la Maîtrise de l'Energie (ADEME, Angers, France) in the framework of PhytEO and DEPHYTOP projects. This work was also carried out under the framework of the Alibiotech project, financed by the European Union, the French State, the French Region of Hauts-de-France, and Triplet project (A2U).

Institutional Review Board Statement: Not applicable.

Informed Consent Statement: Not applicable.

Data Availability Statement: The original contributions presented in the study are publicly available.

Acknowledgments: The authors wish to thank the "Universite du Littoral Côte d'Opale" and the "Pôle Métropolitain de la Côte d'Opale" for providing financial support for R. Raveau's Ph.D. thesis.

Conflicts of Interest: The authors declare no conflict of interest. 


\section{References}

1. Ding, Z.; Wu, J.; You, A.; Huang, B.; Cao, C. Effects of heavy metals on soil microbial community structure and diversity in the rice (Oryza sativa L. subsp. Japonica, Food Crops Institute of Jiangsu Academy of Agricultural Sciences) rhizosphere. Soil Sci. Plant Nutr. 2017, 63, 75-83. [CrossRef]

2. Adamovic, D.; Djalovic, I.; Mrkovacki, N. Microbial abundance in rhizosphere of medicinal and aromatic plant species in conventional and organic growing systems. Ratar. Povrt. 2015, 52, 1-6. [CrossRef]

3. Klaubauf, S.; Inselsbacher, E.; Zechmeister-Boltenstern, S.; Wanek, W.; Gottsberger, R.; Strauss, J.; Gorfer, M. Molecular diversity of fungal communities in agricultural soils from Lower Austria. Fungal Divers. 2010, 44, 65-75. [CrossRef]

4. Bodelier, P.L.E. Toward understanding, managing, and protecting microbial ecosystems. Front. Microbiol. 2011, 2, 1-8. [CrossRef] [PubMed]

5. Jia, T.; Wang, R.; Fan, X.; Chai, B. A comparative study of fungal community structure, diversity and richness between the soil and the phyllosphere of native grass species in a copper tailings dam in Shanxi Province, China. Appl. Sci. 2018, 8, 1297. [CrossRef]

6. Lin, Y.; Xiao, W.; Ye, Y.; Wu, C.; Hu, Y.; Shi, H. Adaptation of soil fungi to heavy metal contamination in paddy fields-A case study in eastern China. Environ. Sci. Pollut. Res. 2020, 27, 27819-27830. [CrossRef] [PubMed]

7. Liang, J.; Liu, J.; Yang, T.; Wang, P.; Zhang, S.; Jia, P.; Liao, B.; Shu, W.; Li, J. Contrasting soil fungal communities at different habitats in a revegetated copper mine wasteland. Soil Ecol. Lett. 2020, 2, 8-19. [CrossRef]

8. Smith, S.; Read, D. Mycorrhizal Symbiosis; Elsevier: Amsterdam, The Netherlands, 2008; ISBN 978-0-12370-526-6.

9. Janoušková, M.; Krak, K.; Vosátka, M.; Püschel, D.; Štorchová, H. Inoculation effects on root-colonizing arbuscular mycorrhizal fungal communities spread beyond directly inoculated plants. PLoS ONE 2017, 12, e0181525. [CrossRef]

10. Dagher, D.J.; De La Providencia, I.E.; Pitre, F.E.; St-Arnaud, M.; Hijri, M. Arbuscular mycorrhizal fungal assemblages significantly shifted upon bacterial inoculation in non-contaminated and petroleum-contaminated environments. Microorganisms 2020, $8,602$. [CrossRef]

11. Gong, Y.; Zhao, D.; Wang, Q. An overview of field-scale studies on remediation of soil contaminated with heavy metals and metalloids: Technical progress over the last decade. Water Res. 2018, 147, 440-460. [CrossRef]

12. Ferrol, N.; Tamayo, E.; Vargas, P. The heavy metal paradox in arbuscular mycorrhizas: From mechanisms to biotechnological applications. J. Exp. Bot. 2016, 67, 6253-6565. [CrossRef]

13. Op De Beeck, M.; Lievens, B.; Busschaert, P.; Rineau, F.; Smits, M.; Vangronsveld, J.; Colpaert, J.V. Impact of metal pollution on fungal diversity and community structures. Environ. Microbiol. 2015, 17, 2035-2047. [CrossRef] [PubMed]

14. Lin, Y.; Ye, Y.; Hu, Y.; Shi, H. The variation in microbial community structure under different heavy metal contamination levels in paddy soils. Ecotoxicol. Environ. Saf. 2019, 180, 557-564. [CrossRef] [PubMed]

15. Järup, L. Hazards of heavy metal contamination. Br. Med. Bull. 2003, 68, 167-182. [CrossRef]

16. Chen, J.; He, F.; Zhang, X.; Sun, X.; Zheng, J.; Zheng, J. Heavy metal pollution decreases microbial abundance, diversity and activity within particle-size fractions of a paddy soil. FEMS Microbiol. Ecol. 2014, 87, 164-181. [CrossRef]

17. Bourceret, A.; Cébron, A.; Tisserant, E.; Poupin, P.; Bauda, P.; Beguiristain, T.; Leyval, C. The Bacterial and Fungal Diversity of an Aged PAH- and Heavy Metal-Contaminated Soil is Affected by Plant Cover and Edaphic Parameters. Microb. Ecol. 2016, 71, 711-724. [CrossRef] [PubMed]

18. Burges, A.; Alkorta, I.; Epelde, L.; Garbisu, C. From phytoremediation of soil contaminants to phytomanagement of ecosystem services in metal contaminated sites. Int. J. Phytoremediat. 2018, 20, 384-397. [CrossRef]

19. Mench, M.J.; Dellise, M.; Bes, C.M.; Marchand, L.; Kolbas, A.; Le Coustumer, P.; Oustrière, N. Phytomanagement and remediation of cu-contaminated soils by high yielding crops at a former wood preservation site: Sunflower biomass and ionome. Front. Ecol. Evol. 2018, 6. [CrossRef]

20. Cundy, A.B.; Bardos, R.P.; Puschenreiter, M.; Mench, M.; Bert, V.; Friesl-Hanl, W.; Müller, I.; Li, X.N.; Weyens, N.; Witters, N.; et al. Brownfields to green fields: Realising wider benefits from practical contaminant phytomanagement strategies. J. Environ. Manag. 2016, 184, 67-77. [CrossRef]

21. Evangelou, M.W.H.; Papazoglou, E.G.; Robinson, B.H.; Schulin, R. Phytomanagement: Phytoremediation and the Production of Biomass for Economic Revenue on Contaminated Land. In Phytoremediation: Management of Environmental Contaminants; Springer: Berlin, Germany, 2015; Volume 1, ISBN 978-3-31910-395-2.

22. Pandey, V.C.; Bajpai, O.; Singh, N. Energy crops in sustainable phytoremediation. Renew. Sustain. Energy Rev. 2016, 54, 58-73. [CrossRef]

23. Bauddh, K.; Singh, B.; Korstad, J. Phytoremediation Potential of Bioenergy Plants; Springer: Berlin, Germany, 2017; ISBN 978-9-81103084-0.

24. Tibaldi, G.; Fontana, E.; Nicola, S. Cultivation practices do not change the Salvia sclarea L. essential oil but drying process does. J. Food Agric. Environ. 2010, 8, 790-794.

25. Grigoriadou, K.; Trikka, F.A.; Tsoktouridis, G.; Krigas, N.; Sarropoulou, V.; Papanastasi, K.; Maloupa, E.; Makris, A.M. Micropropagation and cultivation of Salvia sclarea for essential oil and sclareol production in northern Greece. In Vitro Cell. Dev. Biol. Plant 2020, 56, 51-59. [CrossRef]

26. Lydakis-Simantiris, N.; Fabian, M.; Skoula, M. Cultivation of medicinal and aromatic plants in heavy metal-contaminated soils. Glob. Nest J. 2016, 18, 630-642. [CrossRef] 
27. Angelova, V.R.; Ivanova, R.; Todorov, G.M.; Ivanov, K.I. Potential of Salvia sclarea L. for Phytoremediation of Soils Contaminated with Heavy Metals. Agric. Biosyst. Eng. 2016, 10, 780-790.

28. Zutic, I.; Nitzan, N.; Chaimovitsh, D.; Schechter, A.; Dudai, N. Geographical location is a key component to effective breeding of clary sage (Salvia sclarea) for essential oil composition. Isr. J. Plant Sci. 2016, 63, 134-141. [CrossRef]

29. Aćimović, M.; Kiprovski, B.; Rat, M.; Sikora, V.; Popović, V.; Koren, A.; Brdar-Jokanović, M. Salvia sclarea: Chemical composition and biological activity. J. Agron. Technol. Eng. Manag. 2018, 1, 18-28.

30. Dagher, D.J.; Pitre, F.E.; Hijri, M. Ectomycorrhizal Fungal Inoculation of Sphaerosporella brunnea Significantly Increased Stem Biomass of Salix miyabeana and Decreased Lead, Tin, and Zinc, Soil Concentrations during the Phytoremediation of an Industrial Landfill. J. Fungi 2020, 6, 87. [CrossRef]

31. Antoniadis, V.; Levizou, E.; Shaheen, S.M.; Ok, Y.S.; Sebastian, A.; Baum, C.; Prasad, M.N.V.; Wenzel, W.W.; Rinklebe, J. Trace elements in the soil-plant interface: Phytoavailability, translocation, and phytoremediation-A review. Earth Sci. Rev. 2017, 171, 621-645. [CrossRef]

32. Akyol, T.Y.; Niwa, R.; Hirakawa, H.; Maruyama, H.; Sato, T.; Suzuki, T.; Fukunaga, A.; Sato, T.; Yoshida, S.; Tawaraya, K.; et al. Impact of introduction of arbuscular mycorrhizal fungi on the root microbial community in agricultural fields. Microbes Environ. 2019, 34, 23-32. [CrossRef]

33. Lioussanne, L.; Perreault, F.; Jolicoeur, M.; St-Arnaud, M. The bacterial community of tomato rhizosphere is modified by inoculation with arbuscular mycorrhizal fungi but unaffected by soil enrichment with mycorrhizal root exudates or inoculation with Phytophthora nicotianae. Soil Biol. Biochem. 2010, 42, 473-483. [CrossRef]

34. Koch, A.M.; Antunes, P.M.; Barto, E.K.; Cipollini, D.; Mummey, D.L.; Klironomos, J.N. The effects of arbuscular mycorrhizal (AM) fungal and garlic mustard introductions on native AM fungal diversity. Biol. Invasions 2011, 13, 1627-1639. [CrossRef]

35. Renaut, S.; Daoud, R.; Masse, J.; Vialle, A.; Hijri, M. Inoculation with Rhizophagus irregularis does not alter arbuscular mycorrhizal fungal community structure within the roots of corn, wheat, and soybean crops. Microorganisms 2020, 8, 83. [CrossRef] [PubMed]

36. Janoušková, M.; Krak, K.; Wagg, C.; Štorchová, H.; Caklová, P.; Vosátka, M. Effects of inoculum additions in the presence of a preestablished arbuscular mycorrhizal fungal community. Appl. Environ. Microbiol. 2013, 79, 6507-6515. [CrossRef] [PubMed]

37. Trabelsi, D.; Mhamdi, R. Microbial inoculants and their impact on soil microbial communities: A review. Biomed. Res. Int. 2013, 2013. [CrossRef] [PubMed]

38. Iffis, B.; St-Arnaud, M.; Hijri, M. Petroleum hydrocarbon contamination, plant identity and arbuscular mycorrhizal fungal (AMF) community determine assemblages of the AMF spore-associated microbes. Environ. Microbiol. 2016, 18, 2689-2704. [CrossRef] [PubMed]

39. Dagher, D.J.; de la Providencia, I.E.; Pitre, F.E.; St-Arnaud, M.; Hijri, M. Plant Identity Shaped Rhizospheric Microbial Communities More Strongly Than Bacterial Bioaugmentation in Petroleum Hydrocarbon-Polluted Sediments. Front. Microbiol. 2019, 10, 1-13. [CrossRef]

40. Labidi, S.; Fontaine, J.; Laruelle, F.; Tisserant, B.; Dalpé, Y.; Grandmougin-Ferjani, A.; Douay, F.; Lounès-Hadj Sahraoui, A. Fly ash-aided phytostabilisation of highly trace element polluted topsoils improves the telluric fungal biomass: A long-term field experiment. Appl. Soil Ecol. 2015, 85, 69-75. [CrossRef]

41. Sterckeman, T.; Douay, F.; Proix, N.; Fourrier, H.; Perdrix, E. Assessment of the contamination of cultivated soils by eighteen trace elements around smelters in the north of France. Appl. Soil Ecol. 2002, 85, 173-194. [CrossRef]

42. Sterckeman, T.; Douay, F.; Baize, D.; Fourrier, H.; Proix, N.; Schvartz, C. Référentiel pédo-géochimique du Nord-Pas de Calais: Méthode et principaux résultats. Etude Gest. Sols 2007, 14, 153-168.

43. Raveau, R.; Fontaine, J.; Hijri, M.; Lounès-Hadj Sahraoui, A. The Aromatic Plant Clary Sage Shaped Bacterial Communities in the Roots and in the Trace Element-Contaminated Soil More Than Mycorrhizal Inoculation-A Two-Year Monitoring Field Trial Front. Microbiol. 2020, 11, 1-18. [CrossRef]

44. Raveau, R.; Fontaine, J.; Bert, V.; Perlein, A.; Tisserant, B.; Ferrant, P.; Lounès-Hadj Sahraoui, A. In situ cultivation of aromatic plant species for the phytomanagement of an aged-trace element polluted soil: Plant biomass improvement options and techno-economic assessment of the essential oil production channel. Sci. Total Environ. 2021, 147944. [CrossRef] [PubMed]

45. Yi, X.; Yi, K.; Fang, K.; Gao, H.; Dai, W.; Cao, L. Microbial Community Structures and Important Associations Between Soil Nutrients and the Responses of Specific Taxa to Rice-Frog Cultivation. Front. Microbiol. 2019, 10, 1-12. [CrossRef] [PubMed]

46. Sun, C.; Liu, G.; Xue, S. Interaction between plant competition and rhizospheric bacterial community influence secondary succession of abandoned farmland on the loess plateau of China. Front. Plant Sci. 2018, 9, 1-12. [CrossRef] [PubMed]

47. Abu-Romman, S. Comparison of methods for isolating high quality dna from sage (Salvia officinalis). J. Med. Plants Res. 2011, 5, 938-941.

48. Aleksić, J.M.; Stojanović, D.; Banović, B.; Jančić, R. A simple and efficient DNA isolation method for Salvia officinalis. Biochem. Genet. 2012, 50, 881-892. [CrossRef]

49. Toju, H.; Tanabe, A.S.; Yamamoto, S.; Sato, H. High-coverage ITS primers for the DNA-based identification of ascomycetes and basidiomycetes in environmental samples. PLoS ONE 2012, 7. [CrossRef]

50. Lee, J.; Lee, S.; Young, J.P.W. Improved PCR primers for the detection and identification of arbuscular mycorrhizal fungi. FEMS Microbiol. Ecol. 2008, 65, 339-349. [CrossRef] 
51. Stefani, F.; Bencherif, K.; Sabourin, S.; Lounès-Hadj Sahraoui, A.; Banchini, C.; Séguin, S.; Dalpé, Y. Taxonomic assignment of arbuscular mycorrhizal fungi in an $18 \mathrm{~S}$ metagenomic dataset: A case study with saltcedar (Tamarix aphylla). Mycorrhiza 2020, 30, 243-255. [CrossRef]

52. R Core Team. R: A Language and Environment for Statistical Computing; R Foundation for Statistical Computing: Vienna, Austria, 2019.

53. Martin, M. Cutadapt removes adapter sequences from high-throughput sequencing reads. EMBnet J. 2011. [CrossRef]

54. Wang, Q.; Garrity, G.M.; Tiedje, J.M.; Cole, J.R. Naïve Bayesian classifier for rapid assignment of rRNA sequences into the new bacterial taxonomy. Appl. Environ. Microbiol. 2007, 73, 5261-5267. [CrossRef]

55. Nguyen, N.H.; Song, Z.; Bates, S.T.; Branco, S.; Tedersoo, L.; Menke, J.; Schilling, J.S.; Kennedy, P.G. FUNGuild: An open annotation tool for parsing fungal community datasets by ecological guild. Fungal Ecol. 2016, 20, 241-248. [CrossRef]

56. Callahan, B. Silva taxonomic training data formatted for DADA2 (Silva version 132). Zenodo 2018. [CrossRef]

57. Krüger, M.; Krüger, C.; Walker, C.; Stockinger, H.; Schüßler, A. Phylogenetic reference data for systematics and phylotaxonomy of arbuscular mycorrhizal fungi from phylum to species level. New Phytol. 2012, 193, 970-984. [CrossRef]

58. Lassmann, T.; Frings, O.; Sonnhammer, E.L.L. Kalign2: High-performance multiple alignment of protein and nucleotide sequences allowing external features. Nucleic Acids Res. 2009, 37, 858-865. [CrossRef] [PubMed]

59. Stamatakis, A. RAxML version 8: A tool for phylogenetic analysis and post-analysis of large phylogenies. Bioinformatics 2014, 30, 1312-1313. [CrossRef] [PubMed]

60. Miller, M.A.; Pfeiffer, W.; Schwartz, T. Creating the CIPRES Science Gateway for inference of large phylogenetic trees. In Proceedings of the 2010 Gateway Computing Environments Workshop (GCE), New Orleans, LA, USA, 14 November 2010.

61. Shi, Y.; Qiu, L.; Guo, L.; Man, J.; Shang, B.; Pu, R.; Ou, X.; Dai, C.; Liu, P.; Yang, Y.; et al. K Fertilizers Reduce the Accumulation of Cd in Panax notoginseng (Burk.) F.H. by Improving the Quality of the Microbial Community. Front. Plant Sci. 2020, 11, 1-13. [CrossRef] [PubMed]

62. Torres-Cruz, T.J.; Hesse, C.; Kuske, C.R.; Porras-Alfaro, A. Presence and distribution of heavy metal tolerant fungi in surface soils of a temperate pine forest. Appl. Soil Ecol. 2018, 131, 66-74. [CrossRef]

63. Misra, P.; Maji, D.; Awasthi, A.; Pandey, S.S.; Yadav, A.; Pandey, A.; Saikia, D.; Babu, C.S.V.; Kalra, A. Vulnerability of Soil Microbiome to Monocropping of Medicinal and Aromatic Plants and Its Restoration Through Intercropping and Organic Amendments. Front. Microbiol. 2019, 10, 1-15. [CrossRef]

64. Blackwood, C.B.; Waldrop, M.P.; Zak, D.R.; Sinsabaugh, R.L. Molecular analysis of fungal communities and laccase genes in decomposing litter reveals differences among forest types but no impact of nitrogen deposition. Environ. Microbiol. 2007, 9, 1306-1316. [CrossRef] [PubMed]

65. Luo, Z.B.; Wu, C.; Zhang, C.; Li, H.; Lipka, U.; Polle, A. The role of ectomycorrhizas in heavy metal stress tolerance of host plants. Environ. Exp. Bot. 2014, 108, 47-62. [CrossRef]

66. Kalsotra, T.; Khullar, S.; Agnihotri, R.; Reddy, M.S. Metal induction of two metallothionein genes in the ectomycorrhizal fungus suillus himalayensis and their role in metal tolerance. Microbiology 2018, 164, 868-876. [CrossRef]

67. Shine, A.M.; Shakya, V.P.; Idnurm, A. Phytochelatin synthase is required for tolerating metal toxicity in a basidiomycete yeast and is a conserved factor involved in metal homeostasis in fungi. Fungal Biol. Biotechnol. 2015, 2, 1-13. [CrossRef]

68. Sudhakara Reddy, M.; Prasanna, L.; Marmeisse, R.; Fraissinet-Tachet, L. Differential expression of metallothioneins in response to heavy metals and their involvement in metal tolerance in the symbiotic basidiomycete Laccaria bicolor. Microbiology 2014, 160, 2235-2242. [CrossRef] [PubMed]

69. Foulon, J.; Zappelini, C.; Durand, A.; Valot, B.; Blaudez, D.; Chalot, M. Impact of poplar-based phytomanagement on soil properties and microbial communities in a metal-contaminated site. FEMS Microbiol. Ecol. 2016, 92. [CrossRef] [PubMed]

70. Lopes Leal, P.; Varón-López, M.; Gonçalves de Oliveira Prado, I.; Valentim dos Santos, J.; Fonsêca Sousa Soares, C.R.; Siqueira, J.O.; de Souza Moreira, F.M. Enrichment of arbuscular mycorrhizal fungi in a contaminated soil after rehabilitation. Braz. J. Microbiol. 2016, 47, 853-862. [CrossRef]

71. Yang, Y.; Song, Y.; Scheller, H.V.; Ghosh, A.; Ban, Y.; Chen, H.; Tang, M. Community structure of arbuscular mycorrhizal fungi associated with Robinia pseudoacacia in uncontaminated and heavy metal contaminated soils. Soil Biol. Biochem. 2015, 86, 146-158. [CrossRef]

72. Goldmann, K.; Schröter, K.; Pena, R.; Schöning, I.; Schrumpf, M.; Buscot, F.; Polle, A.; Wubet, T. Divergent habitat filtering of root and soil fungal communities in temperate beech forests. Sci. Rep. 2016, 6, 1-10. [CrossRef] [PubMed]

73. Giraldo, A.; Hernández-Restrepo, M.; Crous, P.W. New plectosphaerellaceous species from Dutch garden soil. Mycol. Prog. 2019, 18, 1135-1154. [CrossRef]

74. Carlucci, A.; Raimondo, M.L.; Santos, J.; Phillips, A.J.L. Plectosphaerella species associated with root and collar rots of horticultural crops in southern Italy. Pers. Mol. Phylogeny Evol. Fungi 2012, 28, 34-48. [CrossRef]

75. Wang, Z.; Li, T.; Wen, X.; Liu, Y.; Han, J.; Liao, Y.; DeBruyn, J.M. Fungal communities in rhizosphere soil under conservation tillage shift in response to plant growth. Front. Microbiol. 2017, 8, 1-11. [CrossRef]

76. Na, X.; Ma, C.; Ma, S.; Ma, X.; Zhu, X.; Xu, P.; Zhu, H.; Cao, X.; Liang, W. Monocropping decouples plant-bacteria interaction and strengthens phytopathogenic fungi colonization in the rhizosphere of a perennial plant species. Plant Soil 2019, 445, 549-564. [CrossRef] 
77. Qu, Z.; Liu, B.; Ma, Y.; Sun, H. Differences in bacterial community structure and potential functions among Eucalyptus plantations with different ages and species of trees. Appl. Soil Ecol. 2020, 149, 103515. [CrossRef]

78. Wei, X.; Wang, X.; Cao, P.; Gao, Z.; Chen, A.J.; Han, J. Microbial Community Changes in the Rhizosphere Soil of Healthy and Rusty Panax ginseng and Discovery of Pivotal Fungal Genera Associated with Rusty Roots. Biomed Res. Int. 2020, 2020. [CrossRef] [PubMed]

79. Puškárová, A.; Bučková, M.; Kraková, L.; Pangallo, D.; Kozics, K. The antibacterial and antifungal activity of six essential oils and their cyto/genotoxicity to human HEL 12469 cells. Sci. Rep. 2017, 7, 1-11. [CrossRef] [PubMed]

80. Pitarokili, D.; Couladis, M.; Petsikos-Panayotarou, N.; Tzakou, O. Composition and antifungal activity on soil-borne pathogens of the essential oil of Salvia sclarea from Greece. J. Agric. Food Chem. 2002, 50, 6688-6691. [CrossRef]

81. Li, X.; Panke-Buisse, K.; Yao, X.; Coleman-Derr, D.; Ding, C.; Wang, X.; Ruan, H. Peanut plant growth was altered by monocropping-associated microbial enrichment of rhizosphere microbiome. Plant Soil 2020, 446, 655-669. [CrossRef]

82. Li, W.H.; Liu, Q.Z. Changes in fungal community and diversity in strawberry rhizosphere soil after 12 years in the greenhouse. J. Integr. Agric. 2019, 18, 677-687. [CrossRef]

83. Iffis, B.; St-Arnaud, M.; Hijri, M. Bacteria associated with arbuscular mycorrhizal fungi within roots of plants growing in a soil highly contaminated with aliphatic and aromatic petroleum hydrocarbons. FEMS Microbiol. Lett. 2014, 358, 44-54. [CrossRef]

84. Hijri, M.; Redecker, D.; MacDonald-Comber Petetot, J.A.; Voigt, K.; Wöstemeyer, J.; Sanders, I.R. Identification and isolation of two ascomycete fungi from spores of the arbuscular mycorrhizal fungus Scutellospora castanea. Appl. Environ. Microbiol. 2002, 68, 4567-4573. [CrossRef] [PubMed]

85. Zappelini, C.; Karimi, B.; Foulon, J.; Lacercat-Didier, L.; Maillard, F.; Valot, B.; Blaudez, D.; Cazaux, D.; Gilbert, D.; Yergeau, E.; et al. Diversity and complexity of microbial communities from a chlor-alkali tailings dump. Soil Biol. Biochem. 2015. [CrossRef]

86. Zhao, M.; Sun, B.; Wu, L.; Wang, F.; Wen, C.; Wang, M.; Liang, Y.; Hale, L.; Zhou, J.; Yang, Y. Dissimilar responses of fungal and bacterial communities to soil transplantation simulating abrupt climate changes. Mol. Ecol. 2019. [CrossRef] [PubMed]

87. Bi, Y.; Zhang, Y.; Zou, H. Plant growth and their root development after inoculation of arbuscular mycorrhizal fungi in coal mine subsided areas. Int. J. Coal Sci. Technol. 2018, 5, 47-53. [CrossRef]

88. Griffiths, B.S.; Philippot, L. Insights into the resistance and resilience of the soil microbial community. FEMS Microbiol. Rev. 2013, 37, 112-129. [CrossRef]

89. Sharma, S.; Kumar, R. Effect of nitrogen on growth, biomass and oil composition of clary sage (Salvia sclarea Linn.) under mid hills of north western Himalayas. Indian J. Nat. Prod. Resour. 2012, 3, 79-83.

90. Abbaszadeh, B.; Safikhani, F.; Layeghhaghighi, M. Effects of Irrigation Interval and Nitrogen Amount on Different Clary Sage (Salvia sclarea L.) Characters in Karaj. J. Med. Plants By-Prod. JMPB 2017, 6, 139-144.

91. Denoroy, P.; Dubrulle, P.; Villette, C.; Colomb, B. REGIFERT, Interpréter les Résultats des Analyses de Terre; Quae, E., Ed.; INRA Editions: Paris, France, 2004; ISBN 978-2-73801-168-8.

92. Karandashov, V.; Bucher, M. Symbiotic phosphate transport in arbuscular mycorrhizas. Trends Plant Sci. 2005, 10, 22-29. [CrossRef] [PubMed]

93. Voß, S.; Betz, R.; Heidt, S.; Corradi, N.; Requena, N. RiCRN1, a crinkler effector from the arbuscular mycorrhizal fungus rhizophagus irregularis, functions in arbuscule development. Front. Microbiol. 2018, 9, 1-18. [CrossRef]

94. Paszkowski, U.; Kroken, S.; Roux, C.; Briggs, S.P. Rice phosphate transporters include an evolutionarily divergent gene specifically activated in arbuscular mycorrhizal symbiosis. Proc. Natl. Acad. Sci. USA 2002, 99, 13324-13329. [CrossRef]

95. Hart, M.M.; Antunes, P.M.; Chaudhary, V.B.; Abbott, L.K. Fungal inoculants in the field: Is the reward greater than the risk? Funct. Ecol. 2017, 32, 126-135. [CrossRef]

96. Saks, Ü.; Davison, J.; Öpik, M.; Vasar, M.; Moora, M.; Zobel, M. Root-colonizing and soil-borne communities of arbuscular mycorrhizal fungi in a temperate forest understorey. Botany 2014, 92, 277-285. [CrossRef]

97. Varela-Cervero, S.; Vasar, M.; Davison, J.; Barea, J.M.; Öpik, M.; Azcón-Aguilar, C. The composition of arbuscular mycorrhizal fungal communities differs among the roots, spores and extraradical mycelia associated with five Mediterranean plant species. Environ. Microbiol. 2015, 17, 2882-2895. [CrossRef] [PubMed]

98. Wang, C.; Zhang, W.; Zhao, C.; Shi, R.; Xue, R.; Li, X. Revegetation by sowing reduces soil bacterial and fungal diversity. Ecol. Evol. 2019, 10, 431-440. [CrossRef]

99. Njeru, E.M.; Avio, L.; Bocci, G.; Sbrana, C.; Turrini, A.; Bàrberi, P.; Giovannetti, M.; Oehl, F. Contrasting effects of cover crops on 'hot spot' arbuscular mycorrhizal fungal communities in organic tomato. Biol. Fertil. Soils 2015, 51, 151-166. [CrossRef]

100. Johnson, D.; Vandenkoornhuyse, P.J.; Leake, J.R.; Gilbert, L.; Booth, R.E.; Grime, J.P.; Young, J.P.W.; Read, D.J. Plant communities affect arbuscular mycorrhizal fungal diversity and community composition in grassland microcosms. New Phytol. 2003, 161, 503-515. [CrossRef] [PubMed]

101. Husband, R.; Herre, E.A.; Turner, S.L.; Gallery, R.; Young, J.P.W. Molecular diversity of arbuscular mycorrhizal fungi and patterns of host association over time and space in a tropical forest. Mol. Ecol. 2002, 11, 2669-2678. [CrossRef] [PubMed]

102. Helgason, T.; Merryweather, J.W.; Denison, J.; Wilson, P.; Young, J.P.W.; Fitter, A.H. Selectivity and functional diversity in arbuscular mycorrhizas of co-occurring fungi and plants from a temperate deciduous woodland. J. Ecol. 2002, 90, 371-384. [CrossRef]

103. Badri, A.; Stefani, F.O.P.; Lachance, G.; Roy-Arcand, L.; Beaudet, D.; Vialle, A.; Hijri, M. Molecular diagnostic toolkit for Rhizophagus irregularis isolate DAOM-197198 using quantitative PCR assay targeting the mitochondrial genome. Mycorrhiza 2016, 26, 721-733. [CrossRef] [PubMed] 